\title{
Ring closing metathesis employing organometallic substrates and the templated synthesis of macrocycles ${ }^{\text {is }}$
}

\author{
Preston A. Chase ${ }^{a}$, Martin Lutz ${ }^{b}$, Anthony L. Spek ${ }^{b}$, \\ Gerard P.M. van Klink ${ }^{\mathrm{a}}$, Gerard van Koten ${ }^{\mathrm{a}, *}$ \\ ${ }^{a}$ Debye Institute, Organic Chemistry and Catalysis, Utrecht University, Padualaan 8, 3584 CH Utrecht, The Netherlands \\ ${ }^{\mathrm{b}}$ Bijvoet Center for Biomolecular Research, Crystal and Structural Chemistry, Utrecht University, Padualaan 8, 3584 CH Utrecht, The Netherlands
}

Available online 18 May 2006

\begin{abstract}
Templation is a well-known strategy for the selective generation of complex products. Ring-closing metathesis, catalyzed by well-characterized $\mathrm{Ru}$ and Mo catalysts, is a powerful method for $\mathrm{C}=\mathrm{C}$ bond formation and has certainly developed into one of the most important modern reactions in organic synthesis and in polymer chemistry. Despite the extensive research on this reaction, the use of organometallic containing substrates is not well-studied. Here, we give a detailed account of our ongoing efforts to employ ring-closing metathesis with bis $(\alpha$-olefin) substituted pyridines in the presence of trimeric metallopincer templates for the selective synthesis of macroheterocycles with ring sizes up to 81 atoms.
\end{abstract}

(C) 2006 Elsevier B.V. All rights reserved.

Keywords: Templated synthesis; Olefin metathesis; Organometallic substrates; Macrocycles; Protecting groups

\section{Introduction}

Olefin metathesis has emerged as one of the prime carbon-carbon bond forming reactions available in the chemist's toolbox [1]. Since the early discoveries by Grubbs [2-4] and Schrock [5] of well-defined ruthenium- and molybdenum-based catalyst systems, respectively, the use of this reaction methodology has experienced unprecedented growth [6,7]. The synthesis of numerous complex organic molecules and natural products [8] has been performed with olefin metathesis integrated into one or more of the key reactions which, in some cases, greatly abbreviate the number of synthetic steps necessary with nonmetathesis based routes [9]. As well, olefin metathesis is now firmly entrenched in polymer chemistry [1,10]. In addition to the original catalysts, a number of research groups have actively

\footnotetext{
A portion of this contribution was presented as a lecture at the 16th International Symposium on Olefin Metathesis and Related Chemistry, August 7-12, 2005, Poznań, Poland. Conference chairman Prof. Bogdan Marciniec and his team are heartily congratulated and greatly thanked for the organization of an excellent and stimulating symposium.

* Corresponding author. Tel.: +31 30 2533120; fax: +31 302523615 .

E-mail addresses: a.1.spek@chem.uu.nl (A.L. Spek),

g.vankoten@chem.uu.nl (G. van Koten).

$U R L:$ http://www.chem.uu.nl/soc.
}

pursued the development of either derivative or novel systems that have opened new areas in this chemistry by improving activity, chemo-, regio- and stereo-selectivity as well as addressing important factors such as catalyst stability, ease of synthesis, recycling and functional group tolerance; [1-9,11-16] see Fig. 1 for a small selection of metathesis catalysts with some selected properties. Recent results with Ru-based systems have also probed the nature of the elusive "active catalytic species"[17] and detailed kinetic studies have helped to unravel the intimate mechanistic details of this important reaction $[18,19]$. While lagging somewhat behind the advances in the metathesis chemistry of alkenes, recent developments in alkyne metathesis show this area to also be of great potential benefit to the above mentioned areas [20,21].

Despite the large body of research in olefin metathesis chemistry, the utility of this reaction in the presence of ancillary transition metal complexes is less explored but attracting increasing interest [22]. As one of the main benefits of metathesis catalysts is their functional group tolerance, it is interesting to determine whether metal containing motifs, such as $\mathrm{M}-\mathrm{C}, \mathrm{M}-\mathrm{X}$, or $\mathrm{M}-\mathrm{P}$ bonds, are also compatible. In addition, due to the large variety of specific geometries available within metal coordination spheres, the potential for directed synthesis of novel products via metal-based templation is also possible. Metalbased templation strategies have been extensively employed in 

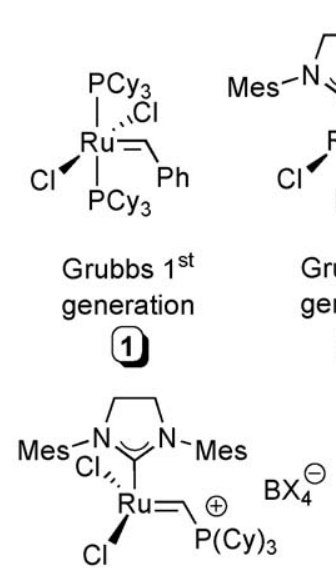

$$
\begin{aligned}
& \text { ultra rapid initiation } \\
& \text { high acitivity } \\
& \text { Romero/ Piers }
\end{aligned}
$$<smiles></smiles>

high activity simple catalyst removal Fogg<smiles></smiles>

Grubbs $2^{\text {nd }}$ generation

(2)<smiles>CN1CCN(C)C1=[Ge](Cl)Cl</smiles>

catalyst stability Hoveyda/ Blechert

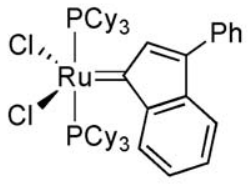

simple synthesis good reactivity Fürstner

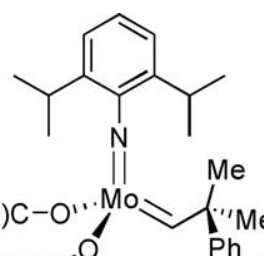

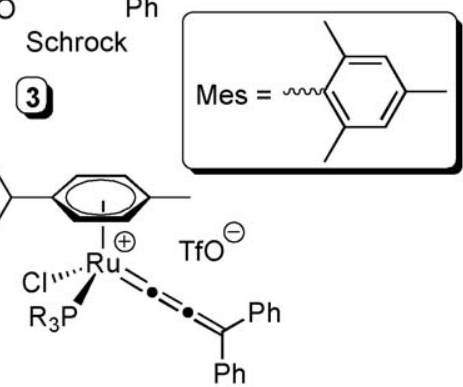

simple synthesis good reactivity Dixneuf/ Fürstner

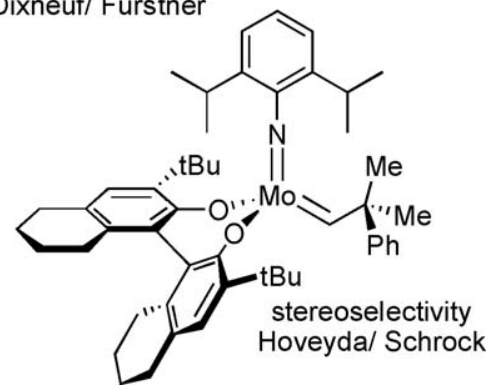

Fig. 1. Selected examples of Ru- and Mo-based olefin metathesis catalysts.

supramolecular chemistry for the generation of mechanically interlocked molecules, such as catenanes, rotaxanes and knots [23-26].

Recent results have shown that both alkene and alkyne metathesis can be performed using either organometallic or coordination compounds as substrates. A pioneering study by Sauvage and Grubbs detailed the generation of catenanes using bis(olefin) appended 9,10-phenanthroline copper complexes via ring-closing metathesis (RCM) and subsequent demetalation, Fig. 2 [27,28]. A molecular knot of similar composition was also reported [29]. A number of results from the Gladysz

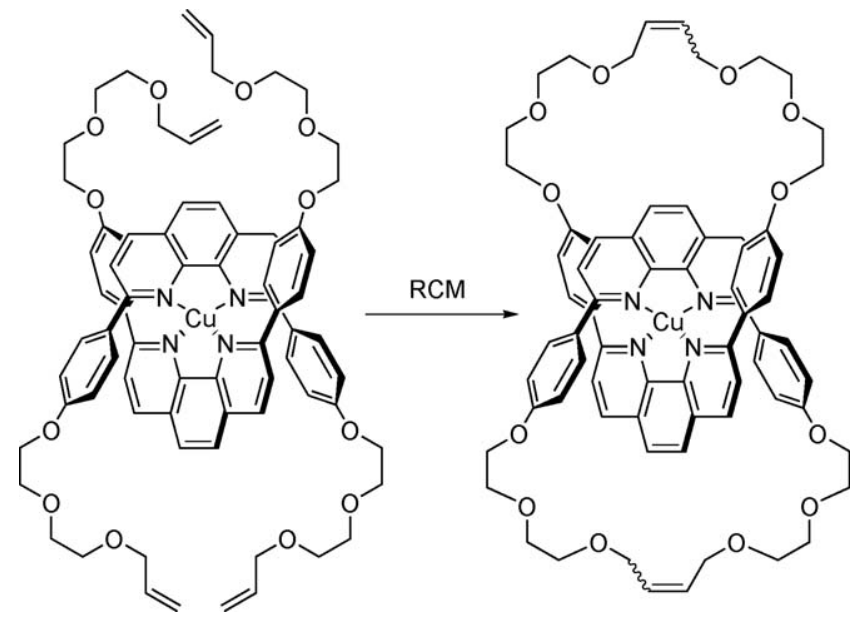

Fig. 2. Cu-templated [2]-catenane synthesis. See refs. [27,28]. group show that unique ligands, such as relatively rare, transspanning diphosphines or macrocyclic monophosphines, as well as bimetallic species can be readily synthesized using RCM methods in conjunction with organometallic substrates [30-35]. Also, complex molecular architectures, such as an Fe-phosphine "molecular gyroscope," can be rapidly assembled in high yields, Fig. 3 [36]. In addition, alkyne metathesis can be employed to generate the alkynyl versions of some of these ligands, Fig. 4 [37,38]. Leigh et al. have recently published the Pd tem-

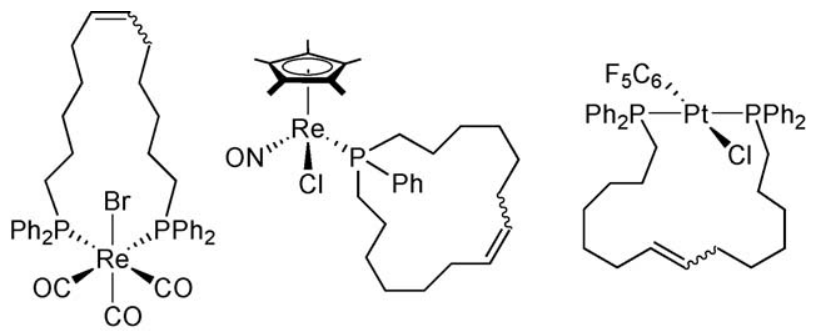

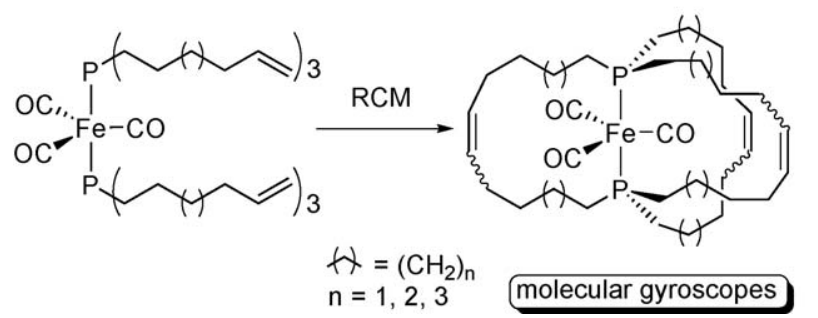

Fig. 3. Selection of compounds from Gladysz formed by alkene metathesis. See refs. [30-36]. 

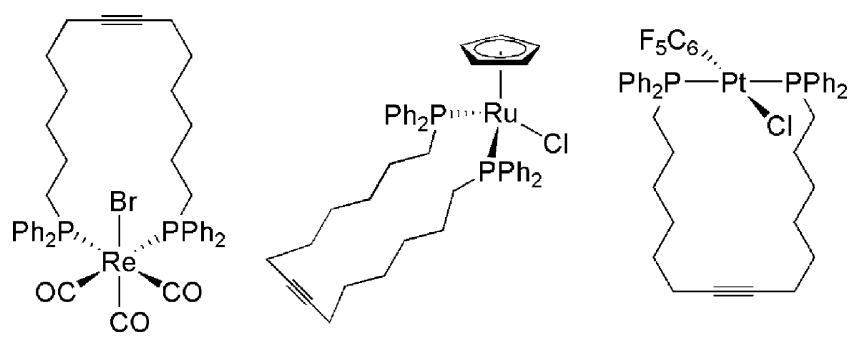

Fig. 4. Selection of compounds from Gladysz formed by alkyne metathesis. See refs. [37,38].

plated synthesis of catenanes [39] and rotaxanes using RCM $[40,41]$.

Our original forays [42-44] into this area stemmed from ongoing interest in the "heterogenization" of homogeneous catalysts by support on large, soluble organic scaffolds, such as dendrimers [45-48]. This renders the catalyst amenable to nanofiltration separation techniques [49,50]. The catalysts studied in this regard are complexes of the well-known "pincer" ligand system [51-56]. Dendritic supports offer many advantages in this area but, due to their flexible nature, are not retained by nanofiltration membranes to the same extent as rigid molecules of similar (or lesser) molecular weight. In part to address this, a number of rigid, shape persistent pincer containing "cartwheel" type complexes [57-60] were synthesized in which the pincer groups surround an arene core, Fig. 5. In addition to their increased levels of retention in nanofiltration, these rigid, diskshaped complexes are also potential candidates for template molecules. Their fixed structures allow strict control of the preorganization of reactants and the coordination chemistry of the pincer ligated metal complexes is well-studied, simplifying the choice for potential anchoring ligands.

To fully realize the potential templating ability of these rigid pincer systems, a number of important criteria need to be considered. First, as the synthesis of these multi-metallic pincer complexes is relatively laborious, the template should be potentially recyclable and obtained pure in a limited number of steps. Second, detachment of the product from the template and subsequent separation of the template from the released product must be facile. Finally, the selectivity of the reaction for a single product should be high. We have found that all these requirements can be met by employing bis( $\alpha$-olefin)pyridines ligated to $\mathrm{Pd}$ or Pt pincer complexes. Here, we give a detailed account of our previous work in this area along with a selection of new results.

\section{Experimental}

\subsection{General considerations}

All reactions were performed under an atmosphere of dry, oxygen-free nitrogen using Schlenk techniques or in a nitrogen-filled MBraun 150 G1 glovebox unless otherwise noted. Pentane and toluene were dried over Na sand, THF and diethyl ether were dried over $\mathrm{Na} /$ benzophenone, dimethylformamide (DMF) was dried over $\mathrm{CaH}_{2}$ and all solvents were freshly distilled under nitrogen prior to use. $\mathrm{CD}_{2} \mathrm{Cl}_{2}$ was purchased from Cambridge Isotope Laboratories, dried over $\mathrm{CaH}_{2}$, distilled prior to use and stored in a Schlenk flask over $4 \AA$ molecular sieves under nitrogen. All other deuterated solvents (Cambridge Isotope Laboratories) were used as received. 1D-NMR spectra $\left[{ }^{1} \mathrm{H}(300.1 \mathrm{MHz})\right.$ and ${ }^{13} \mathrm{C}\left\{{ }^{1} \mathrm{H}\right\}$

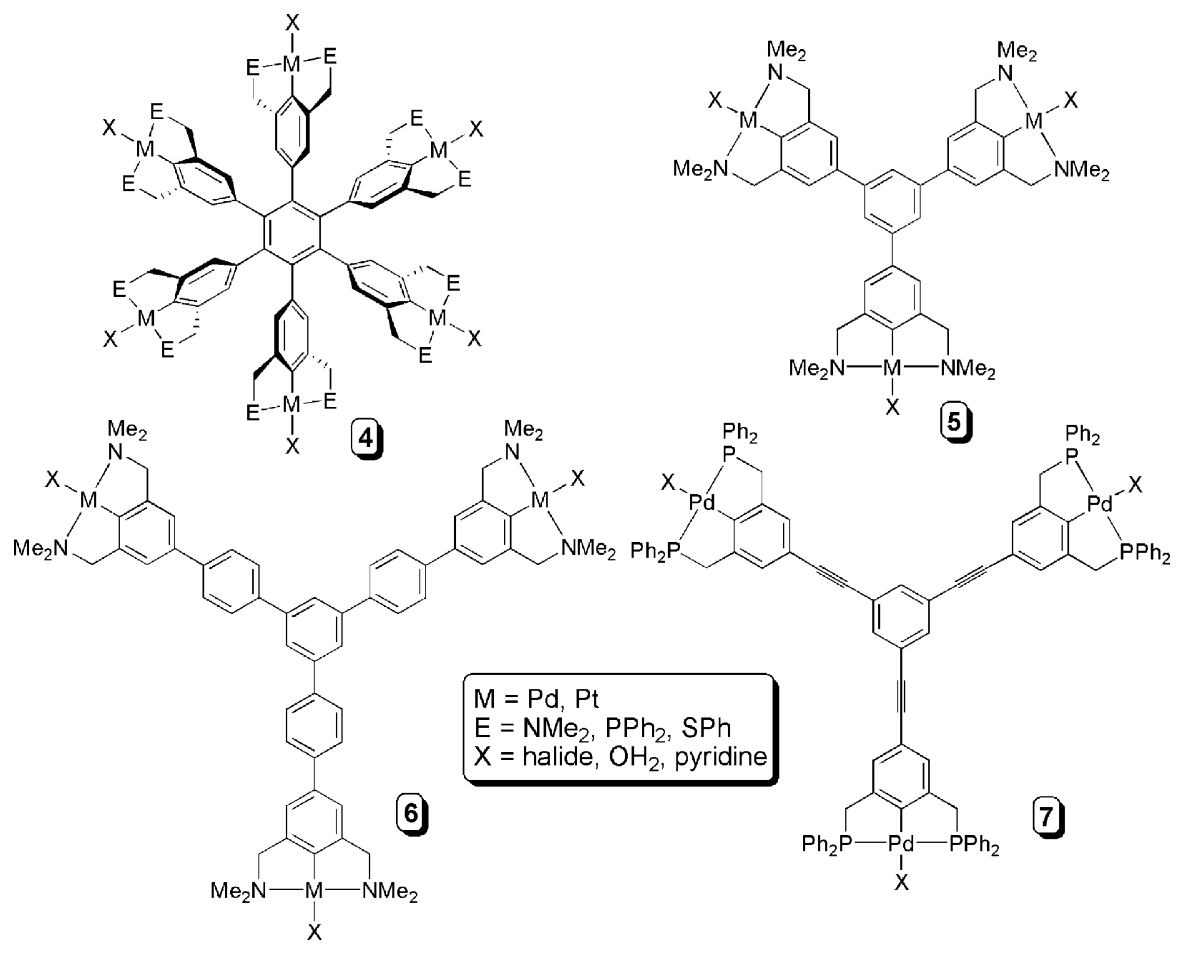

Fig. 5. Structures of selected "cartwheel" pincer complexes. 
$(75.5 \mathrm{MHz})]$ were recorded on a Varian INova $300 \mathrm{MHz}$ spectrometer. Chemical shift values are reported in $\mathrm{ppm}(\delta)$ and referenced internally to residual solvent signals $\left({ }^{1} \mathrm{H},{ }^{13} \mathrm{C}\right)$. Coupling constants $(J)$ are given in Hz. Elemental analyses were performed by $\mathrm{H}$. Kolbe Microanalysis Laboratories, Mülheim a/d Ruhr, Germany. GC-MS experiments were performed with a Perkin-Elmer Autosystem XL gas chromatograph interfaced with a Turbomass mass spectrometer. The injector was initially held at $50^{\circ} \mathrm{C}$ and the temperature is ramped at $20^{\circ} \mathrm{C} / \mathrm{min}$ and held at $280^{\circ} \mathrm{C}$ for $60 \mathrm{~min}$. The compounds [2,6bis(dimethylaminomethyl)-1-phenyl]platinium bromide ([PtBr$(\mathrm{NCN})]), \quad\{[2,6-$ bis(dimethylaminomethyl)-1-phenyl](aqua)platinium $\}$ tetrafluoro borate $\left(\left[\mathrm{PtOH}_{2}(\mathrm{NCN})\right]\left[\mathrm{BF}_{4}\right]\right)$ [61] and 2,6-dibromo-3,5-methylpyridine [62] were synthesized by literature procedures. Metathesis catalysts $\mathbf{1 , 2}$ and $\mathbf{3}$ were purchased from Strem Chemicals. All other reagents were purchased from Acros or Aldrich and used as received. The preparation of all complexes not specifically listed here can be found in the literature [63-66].

\subsection{Alternate synthesis of 2,6-diethoxypyridine (18h)}

Na metal ( $0.80 \mathrm{~g}, 35 \mathrm{mmol}$, excess) was dissolved in degassed $100 \%$ ethanol $(30 \mathrm{ml})$ under $\mathrm{N}_{2}$. Solid 2,6-dibromopyridine $(1.89 \mathrm{~g}, 7.98 \mathrm{mmol})$ was added and the mixture heated to reflux for $3 \mathrm{~h}$. The solvent was removed and dry DMF $(20 \mathrm{ml})$ was added via syringe and the reaction was heated to $120^{\circ} \mathrm{C}$ overnight. After cooling to room temperature (RT), all volatiles were removed in vacuo and diethyl ether $(50 \mathrm{ml})$ and water $(50 \mathrm{ml})$ were added slowly. The light yellow organic layer was separated from the red aqueous layer and the aqueous layer was washed with diethyl ether $(3 \times 50 \mathrm{ml})$. The combined organics were washed with water $(4 \times 70 \mathrm{ml})$ and with brine $(1 \times 100 \mathrm{ml})$ to help remove residual DMF. The organics were dried over $\mathrm{MgSO}_{4}$, filtered and dried for $2 \mathrm{~h}$ in vacuo to obtain the product as a light yellow oil that was used without further purification. Yield $1.04 \mathrm{~g}, 78 \%$. The NMR matches that of the previously reported synthesis [67]. ${ }^{\mathbf{1}} \mathrm{H}$ NMR $\left(\mathrm{C}_{6} \mathrm{D}_{6}\right): \delta 7.08(\mathrm{t}, 1 \mathrm{H}$, ${ }^{3} J_{\mathrm{H}-\mathrm{H}}=8.0$, para $\left.-\mathrm{H}\right), 6.28\left(\mathrm{~d}, 2 \mathrm{H},{ }^{3} \mathrm{~J}_{\mathrm{H}-\mathrm{H}}=8.1\right.$, meta $\left.-\mathrm{H}\right), 4.22(\mathrm{q}$, $\left.4 \mathrm{H},{ }^{3} J_{\mathrm{H}-\mathrm{H}}=7.2, \mathrm{OCH}_{2}\right), 1.20\left(\mathrm{t}, 6 \mathrm{H},{ }^{3} J_{\mathrm{H}-\mathrm{H}}=7.2, \mathrm{OCH}_{2} \mathrm{CH}_{3}\right)$. ${ }^{13} \mathbf{C}$ NMR $\left(\mathrm{C}_{6} \mathrm{D}_{6}\right): \delta 163.4(\mathrm{ArCO}), 141.1(p-\mathrm{ArCH}), 101.7(m-$ $\mathrm{ArCH}), 61.5\left(\mathrm{OCH}_{2}\right), 14.8\left(\mathrm{OCH}_{2} \mathrm{CH}_{3}\right)$. GC-MS $(\mathrm{m} / z): 167$ $\left(\mathrm{M}^{+}\right)$.

\subsection{Synthesis of \\ 2,6-bis(dec-9-enyl-1-oxy)-3,5-dimethylpyridine (24a)}

To a stirred suspension of $\mathrm{Na}$ metal $(0.37 \mathrm{~g}, 16 \mathrm{mmol})$ in dry THF $(50 \mathrm{ml})$ was added neat 9-decene-1-ol $(2.5 \mathrm{~g}, 16 \mathrm{mmol})$ via syringe. The reaction mixture was refluxed overnight until all the Na metal had reacted. All volatiles were removed in vacuo and a solution of 2,6-dibromo-3,5-dimethylpyridine in dry DMF $(20 \mathrm{ml})$ was added via cannula. The flask was rinsed with DMF $(2 \times 15 \mathrm{ml})$. The reaction was heated to $110^{\circ} \mathrm{C}$ for 3 days during which the white alkoxide dissolves and the reaction becomes reddish brown. After cooling, all volatiles were removed in vacuo, the residue was dissolved in water $(100 \mathrm{ml})$ and extracted with diethyl ether $(3 \times 75 \mathrm{ml})$. The combined organics were washed with water $(2 \times 100 \mathrm{ml})$ then brine $(1 \times 100 \mathrm{ml})$. The organic layer was dried over $\mathrm{MgSO}_{4}$, filtered and the solvent removed in vacuo. The product was vacuum distilled (flame, liquid $\mathrm{N}_{2}$ trap, static vacuum) to yield the product as a thick, light yellow oil. Yield: $1.7 \mathrm{~g}, 51 \% .{ }^{1} \mathbf{H}$ NMR $\left(\mathrm{CDCl}_{3}\right): \delta 7.10(\mathrm{~s}$, $1 \mathrm{H}, \mathrm{py}), 5.81\left(\mathrm{~m}, 2 \mathrm{H}, \mathrm{CH}=\mathrm{CH}_{2}\right), 4.98\left(\mathrm{~m}, 2 \times 2 \mathrm{H}, \mathrm{CH}=\mathrm{CH}_{2}\right)$, $4.26\left(\mathrm{t}, 4 \mathrm{H},{ }^{3} \mathrm{~J}_{\mathrm{H}-\mathrm{H}}=6.8, \mathrm{OCH}_{2}\right), 2.06\left(\mathrm{~s}, 6 \mathrm{H}, \mathrm{pyCH}_{3}\right), 1.75$ (m, $\left.4 \mathrm{H}, \mathrm{OCH}_{2} \mathrm{CH}_{2}\right), 1.32$ (br s, $\left.24 \mathrm{H}, \mathrm{CH}_{2}\right) .{ }^{13} \mathbf{C}\left\{{ }^{1} \mathbf{H}\right\}$ NMR $\left(\mathrm{CDCl}_{3}\right): \delta 158.3(\mathrm{ArCO}), 142.3(\mathrm{ArCH}), 139.3(\mathrm{ArCMe}), 114.4$ $(\mathrm{CH}=), 109.9\left(\mathrm{CH}_{2}=\right), 65.8\left(\mathrm{OCH}_{2}\right), 34.0\left(\mathrm{pyCH}_{3}\right), 29.6-29.1$ $\left(6 \times \mathrm{CH}_{2}\right), 26.3\left(\mathrm{CH}_{2}\right)$. Anal. Calcd: C 78.02, H 10.91, N 3.37. Found: C 78.37, H 10.20, N 3.78.

\subsection{Synthesis of 2,6-diethoxy-3,5-dimethylpyridine (24b)}

Na metal ( $0.69 \mathrm{~g}, 30 \mathrm{mmol}$, approximately three times excess) was added to freshly distilled dry ethanol $(30 \mathrm{ml})$ at $0^{\circ} \mathrm{C}$. The solution was stirred at room temperature until all the $\mathrm{Na}$ had dissolved $(20 \mathrm{~min})$ and then solid 2,6-dibromo-3,5dimethylpyridine $(1.42 \mathrm{~g}, 5.3 \mathrm{mmol})$ was added in one portion. The mixture was heated to reflux for $16 \mathrm{~h}^{1}$ All volatiles were removed in vacuo and dry DMF $(30 \mathrm{ml})$ was introduced via syringe and mixture was heated to $120^{\circ} \mathrm{C}$ for $16 \mathrm{~h}$. All volatiles were removed in vacuo and wet diethyl ether $(50 \mathrm{ml})$ and water $(50 \mathrm{ml})$ were added slowly. The layers were separated and the aqueous layer was extracted with diethyl ether $(3 \times 50 \mathrm{ml})$. The combined organic layers were washed with water $(4 \times 50 \mathrm{ml})$, brine $(1 \times 50 \mathrm{ml})$ and the organic layer was dried over $\mathrm{MgSO}_{4}$, filtered and the solvent removed in vacuo. After drying for one additional hour under high vacuum $\left(10^{-6}\right.$ torr) to remove residual DMF, the product was obtained as a light yellow oil and used without further purification. Yield $0.84 \mathrm{~g}(81 \%) .{ }^{\mathbf{1}} \mathbf{H}$ NMR $\left(\mathrm{CDCl}_{3}\right): \delta 7.10(\mathrm{~s}, 1 \mathrm{H}, \mathrm{Ar} H), 4.33\left(\mathrm{q}, 4 \mathrm{H},{ }^{3} J_{\mathrm{H}-\mathrm{H}}=7.0, \mathrm{OCH}_{2}\right)$, $2.08\left(\mathrm{~s}, 6 \mathrm{H}, \mathrm{ArCH}_{3}\right), 1.37$ (t, $\left.6 \mathrm{H},{ }^{3} J_{\mathrm{H}-\mathrm{H}}=7.2, \mathrm{OCH}_{2} \mathrm{CH}_{3}\right)$. ${ }^{13} \mathbf{C}\left\{{ }^{1} \mathbf{H}\right\}$ NMR $\left(\mathrm{CDCl}_{3}\right): \delta 158.1(\mathrm{ArCO}), 142.3(\mathrm{ArCH}), 109.9$ $\left(\mathrm{ArCCH}_{3}\right), 61.4\left(\mathrm{OCH}_{2}\right), 15.1\left(\mathrm{OCH}_{2} \mathrm{CH}_{3}\right), 14.6\left(\mathrm{ArCH}_{3}\right)$. ${ }^{13} \mathrm{C} \mathrm{NMR}\left(\mathrm{CDCl}_{3}\right)$ : $\delta 158.1(\mathrm{~m}, \mathrm{ArCO}), 142.2$ (d of septets, ${ }^{1} J_{\mathrm{C}-\mathrm{H}}=155,{ }^{2} J_{\mathrm{C}-\mathrm{H}}=4.9, \mathrm{ArCH}$ ), 109.9 (quintet, ${ }^{2} J_{\mathrm{C}-\mathrm{H}}=6.2$, $\left.\mathrm{ArCCH}_{3}\right), 61.4\left(\mathrm{t}\right.$ of q, $\left.{ }^{1} J_{\mathrm{C}-\mathrm{H}}=146,{ }^{2} J_{\mathrm{C}-\mathrm{H}}=4.4, \mathrm{OCH}_{2}\right), 15.1$ (q of $\left.\mathrm{t},{ }^{1} J_{\mathrm{C}-\mathrm{H}}=126,{ }^{2} J_{\mathrm{C}-\mathrm{H}}=4.4, \mathrm{OCH}_{2} \mathrm{CH}_{3}\right), 14.6$ (q of $\mathrm{d}$, ${ }^{1} J_{\mathrm{C}-\mathrm{H}}=127,{ }^{2} J_{\mathrm{C}-\mathrm{H}}=4.6, \mathrm{ArCH}_{3}$ ). Anal. Calcd: C 67.66, H 8.78, N 7.17, Found: C 67.51, H 8.67, N 7.22.

\subsection{Synthesis of [(2,6-bis(ethoxy)pyridine) $\operatorname{Pt}(\mathrm{NCN})]\left[\mathrm{BF}_{4}\right]$ (27)}

To a slurry of $\mathrm{AgBF}_{4}(0.415 \mathrm{~g}, 2.13 \mathrm{mmol})$ in dry $\mathrm{CH}_{2} \mathrm{Cl}_{2}$ $(10 \mathrm{ml})$ was added a solution of $[\mathrm{PtBr}(\mathrm{NCN})](0.76 \mathrm{~g}, 1.6 \mathrm{mmol})$ and 2,6-bis(ethoxy)pyridine $(0.27 \mathrm{~g}, 1.6 \mathrm{mmol})$ in $\mathrm{CH}_{2} \mathrm{Cl}_{2}$ $(10 \mathrm{ml})$ via cannula. The reaction mixture was stirred overnight

\footnotetext{
${ }^{1}$ This resulted in exclusive formation of the singly substituted product 2bromo-3,5-dimethyl-6-ethoxypyridine, identified after aqueous work up of a $1.0 \mathrm{ml}$ aliquot of the reaction mixture. ${ }^{1} \mathrm{H} \mathrm{NMR}\left(\mathrm{CDCl}_{3}\right): \delta 7.19(\mathrm{~s}, 1 \mathrm{H}, \mathrm{Ar} H)$, $4.34\left(\mathrm{q}, 2 \mathrm{H},{ }^{3} J_{\mathrm{H}-\mathrm{H}}=7.0, \mathrm{OCH}_{2}\right), 2.24\left(\mathrm{~s}, 3 \mathrm{H}, \mathrm{ArCH}_{3}\right), 2.10\left(\mathrm{~s}, 3 \mathrm{H}, \mathrm{ArCH}_{3}\right)$, $1.37\left(\mathrm{t}, 3 \mathrm{H},{ }^{3} J_{\mathrm{H}-\mathrm{H}}=7.2, \mathrm{OCH}_{2} \mathrm{CH}_{3}\right)$.
} 
with protection from light. The reaction mixture was filtered over celite and the solvent removed under reduced pressure. The product was purified by precipitation by dropwise addition of diethyl ether $(50 \mathrm{ml})$ over $30 \mathrm{~min}$ to a stirred $\mathrm{CH}_{2} \mathrm{Cl}_{2}$ (wet, $15 \mathrm{ml}$ ) solution of product. The white precipitate was isolated by centrifugation and dried in vacuo. Yield: $0.98 \mathrm{~g}, 94 \%$. X-ray quality crystals were obtained by slow evaporation of a $\mathrm{CH}_{2} \mathrm{Cl}_{2}$ solution in air. ${ }^{1} \mathbf{H}$ NMR $\left(\mathrm{CD}_{2} \mathrm{Cl}_{2}\right): \delta 8.02\left(\mathrm{t}, 1 \mathrm{H},{ }^{3} J_{\mathrm{H}-\mathrm{H}}=8.3\right.$, py), $7.05\left(\mathrm{t}, 1 \mathrm{H},{ }^{3} J_{\mathrm{H}-\mathrm{H}}=7.2, \mathrm{NCN}\right), 6.91\left(\mathrm{~d}, 2 \mathrm{H},{ }^{3} J_{\mathrm{H}-\mathrm{H}}=7.2\right.$, $\mathrm{NCN}), 6.71\left(\mathrm{~d}, 2 \mathrm{H},{ }^{3} J_{\mathrm{H}-\mathrm{H}}=8.1\right.$, py), $4.32\left(\mathrm{q}, 4 \mathrm{H},{ }^{3} J_{\mathrm{H}-\mathrm{H}}=6.9\right.$, $\left.\mathrm{OCH}_{2}\right), 4.10\left(\mathrm{~s}, 4 \mathrm{H}, \mathrm{CH}_{2} \mathrm{~N},{ }^{199} \mathrm{Pt}\right.$ satellites $\left.{ }^{3} \mathrm{~J}_{\mathrm{H}-\mathrm{Pt}}=41\right), 2.82(\mathrm{~s}$, $12 \mathrm{H}, \mathrm{NMe}_{2},{ }^{199} \mathrm{Pt}$ satellites $\left.{ }^{3} J_{\mathrm{H}-\mathrm{Pt}}=39\right), 1.53\left(\mathrm{t}, 6 \mathrm{H},{ }^{3} J_{\mathrm{H}-\mathrm{H}}=6.9\right.$, $\left.\mathrm{OCH}_{2} \mathrm{CH}_{3}\right) \cdot{ }^{13} \mathbf{C}\left\{{ }^{1} \mathbf{H}\right\}$ NMR $\left(\mathrm{CDCl}_{3}\right): \delta 163.4$ (pyCO), 145.6 (p-pyCH), $144.4\left(\mathrm{ArC}-\mathrm{CH}_{2}\right), 143.9\left(\mathrm{ArC}-\mathrm{Pt},{ }^{199} \mathrm{Pt}\right.$ coupling not observed), 124.7 ( $p$-ArCH), 120.1 ( $m$-ArCH), 100.9 (m-pyCH), $77.6\left(\mathrm{CH}_{2} \mathrm{~N},{ }^{3} J_{\mathrm{C}-\mathrm{Pt}}=64\right), 66.1\left(\mathrm{OCH}_{2}\right), 54.5\left(\mathrm{NCH}_{3},{ }^{199} \mathrm{Pt}\right.$ coupling obscured by solvent signal), $14.9\left(\mathrm{CH}_{2} \mathrm{CH}_{3}\right)$. Anal. Calcd: C 39.39, H 5.04, N 6.56; Found C 39.48, H 5.15, N 6.44.

\subsection{Details of crystallographic characterization of $\mathbf{2 7}$}

$\left[\mathrm{C}_{21} \mathrm{H}_{32} \mathrm{~N}_{3} \mathrm{O}_{2} \mathrm{Pt}\right] \mathrm{BF}_{4}, \quad \mathrm{Fw}=640.40, \quad$ colourless block, $0.48 \mathrm{~mm} \times 0.48 \mathrm{~mm} \times 0.48 \mathrm{~mm}, \quad$ orthorhombic, $\quad \mathrm{P} 2{ }_{1} 22_{1}$ (no. 19), $a=12.9401(1), \quad b=13.2573(1), \quad c=14.1582(1) \AA$, $V=2428.85(3) \AA^{3}, Z=4, D_{\text {calc }}=1.751 \mathrm{~g} / \mathrm{cm}^{3}, \mu=5.830 \mathrm{~mm}^{-1}$. 57,101 reflections were measured at a temperature of $150(2) \mathrm{K}$ up to a resolution of $(\sin \theta / \lambda)_{\max }=0.65 \AA^{-1}$ on a Nonius KappaCCD diffractometer with rotating anode and graphite monochromator $(\lambda=0.71073 \AA)$. An absorption correction based on multiple measured reflections was applied (0.043-0.060 correction range). Five thousand five hundred and seventy-eight reflections were unique $\left(R_{\mathrm{int}}=0.034\right)$. The structure was solved with automated Patterson Methods [68] and refined with SHELXL-97 [69] on $F^{2}$ of all reflections. Non-hydrogen atoms were refined freely with anisotropic displacement parameters. Hydrogen atoms were introduced in calculated positions and refined as rigid groups. Two hundred and ninety-five parameters were refined with no restraints. R1/wR2 [I>2 $\sigma(I)]$ : $0.0118 / 0.0270$. R1/wR2 [all refl.]: $0.0122 / 0.0270 . S=1.072$. Flack parameter [70] $x=-0.017(3)$. Residual electron density between -0.47 and $0.56 \mathrm{e} / \AA^{3}$. Geometry calculations, drawings and checking for higher symmetry were performed with the PLATON package [71].

Crystallographic data for this paper have been deposited with the Cambridge Crystallographic Data Centre, CCDC No. 283419 (27). Copies of this information may be obtained free of charge from The Director, CCDC, 12 Union Road, Cambridge, CB2 1EZ, UK (fax: +44 12233360333 or e-mail: deposit@ccdc.cam.ac.uk or www: http://www.ccdc.cam.ac.uk).

\subsection{General procedure of RCM reactions with unprotected pyridines}

$\operatorname{Bis}(\alpha$-olefin $)$ substituted pyridine (18a, $0.0488 \mathrm{~g}, 0.13 \mathrm{mmol})$ was weighed into a two-necked, $50 \mathrm{ml}$ round bottom flask which was fitted with a condenser and a rubber septum. After evacua- tion and introduction of an $\mathrm{N}_{2}$ atmosphere, dry $\mathrm{CH}_{2} \mathrm{Cl}_{2}(30 \mathrm{ml})$ was added via syringe and the mixture heated to reflux. Metathesis catalyst $(\mathbf{1}, 5.3 \mathrm{mg}, 6.3 \mu \mathrm{mol}, 5 \mathrm{~mol} \%)$ was dissolved separately in dry $\mathrm{CH}_{2} \mathrm{Cl}_{2}(2 \mathrm{ml})$ in the glovebox and placed in a syringe capped with a rubber septum. The catalyst solution was injected into the reaction (total volume $\mathrm{CH}_{2} \mathrm{Cl}_{2}=32 \mathrm{ml}$, $[p y]=0.004 \mathrm{M}$ ) and aliquots of the reaction were taken periodically. The aliquots were quenched with acetone, dried in vacuo and analyzed by ${ }^{1} \mathrm{H}$ NMR spectroscopy and GC-MS.

\subsection{NMR scale olefin isomerization investigation}

In the glovebox, $\left[\left(\mathrm{H}_{2} \mathrm{O}\right) \mathrm{Pt}(\mathrm{NCN})\right]\left[\mathrm{BF}_{4}\right] \quad(\mathbf{2 5}) \quad(6.8 \mathrm{mg}$, $14 \mu \mathrm{mol})$ was weighed into an NMR tube and dissolved in $\mathrm{CD}_{2} \mathrm{Cl}_{2}(0.64 \mathrm{~g})$. The tube was capped with a rubber septum and removed from the glovebox. Neat 1-octene $(44 \mu \mathrm{l}, 0.28 \mathrm{mmol})$ was syringed into the NMR tube and the tube place in an oil bath preheated to $45^{\circ} \mathrm{C}$.

\section{Results and discussion}

\subsection{Preliminary studies with monomeric pincer-pyridine complexes}

Before attempts at templation studies, tests on the reactivity of simple, monomeric pincer-pyridine complexes in RCM reactions were performed to investigate the scope and applicability of this methodology [66]. One of the first issues addressed was the development of potential pyridine complexation/detachment protocols. As shown in Scheme 1, various cationic pincer-pyridine complexes can be conveniently synthesized by reaction of the corresponding pincer-metal halides with bis( $\alpha$-olefin) substituted pyridines in the presence of $\mathrm{AgBF}_{4}$. The pyridine ligands are simply detached by treatment with excess $\mathrm{NaX}(\mathrm{X}=$ halide $)$ in a biphasic system of $\mathrm{CH}_{2} \mathrm{Cl}_{2} / \mathrm{H}_{2} \mathrm{O}$. Both reactions are quantitative and the pincer-metal halide can be simply separated from the isolated organic layer by precipitation with hexanes. Thus, two of our criteria for an efficient template, simple complexation/detachment of the reactants/products and template recycling, have been realized.

The nature of the metal center and pincer ligand were found to affect the course of the metathesis reaction. Much of the utility of the pincer system stems from the ability to easily vary

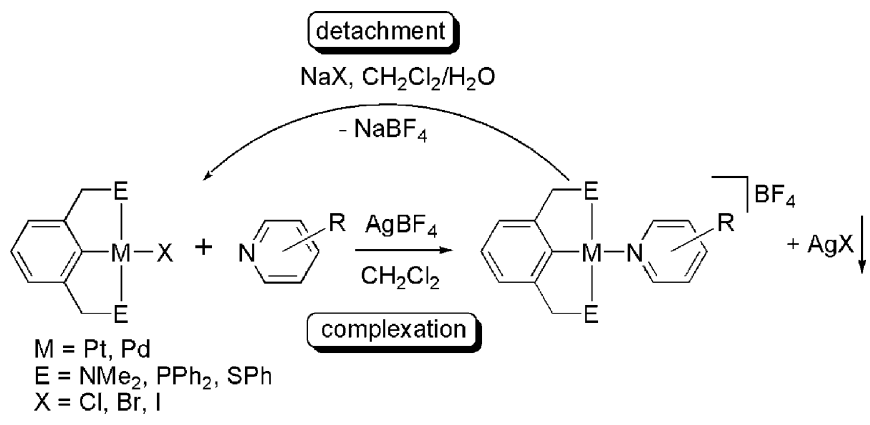

Scheme 1. Complexation and detachment of pyridines to and from metallopincers. 


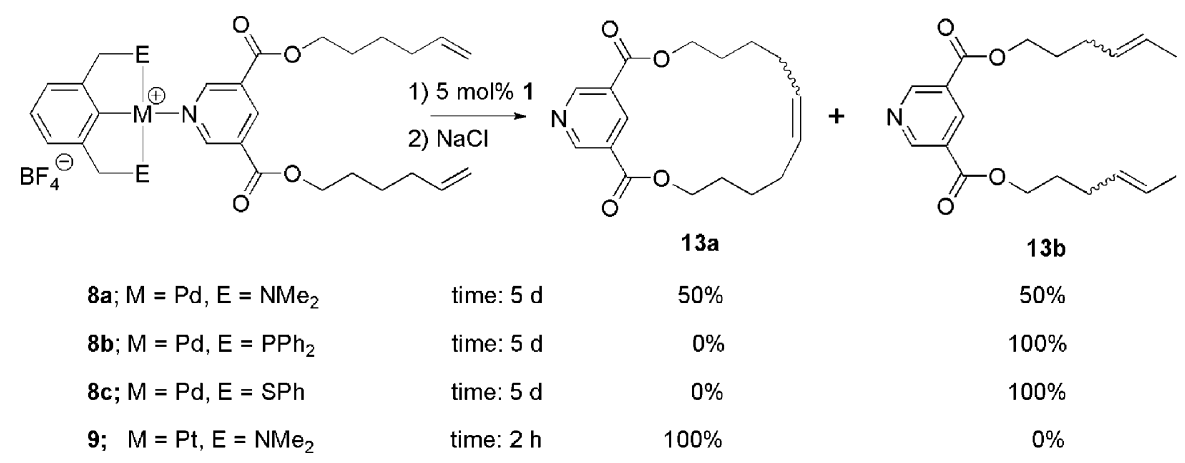

Scheme 2. Reactivity of various pincer-metal complexes of 3,5-substituted pyridines.

its properties by alteration of steric and electronic parameters by, for example, change of the ligating groups. Pyridine ligated Pd complexes of various ECE pincers (8) were employed as initial substrates in RCM with the first generation Grubbs catalyst 1, Scheme 2 [65]. While the terminal alkenes in PCPand SCS-Pd pyridine complexes $\mathbf{8 b}$ and $\mathbf{8 c}$, respectively, only underwent olefin isomerization (vide infra), the $\alpha$-olefins in the NCN-Pd complex 8a reacted cleanly but the RCM product 13a was obtained in only $50 \%$ yield. The remaining products contained the internally isomerized species observed for $\mathbf{8 b}$ and 8c. However, by changing the coordinating metal from $\mathrm{Pd}$ to $\mathrm{Pt}$ (complex 9), the yield of the 13a was now essentially quantitative. Of note is that further RCM with the isomerized products was not observed as $\mathbf{1}$ is relatively unreactive towards internal olefins [1].

Now that the optimized system, an NCN-Pt complex, for performing the RCM reaction had been uncovered, the effect on variation of the position of the $\alpha$-olefins on the pyridine ring was examined [66]. $\alpha$-Olefins of a 5-hexenyl carboxylate group in a 3,5-substitution pattern were quite efficiently ring closed with 1 after only $2 \mathrm{~h}$. Changing to a 2,6- orientation of a 5-hexenyl-1-oxy group precipitously dropped the yield of the RCM product with a concomitant boost in the amount of iso- merized product, Scheme 3. Over $30 \mathrm{~h}$, the yield of the RCM product 14a was only $7 \%$ for the NCN-Pt system 11 with the remaining $93 \%$ of pyridine recovered as the internally isomerized product $14 \mathbf{b}$. The NCN-Pd complex 10 gave similar results after 5 days with $6 \% \mathrm{RCM}$, and $94 \%$ isomerization. Clearly, the alkyl chains are simply not long enough to overcome the steric protection imposed by the pincer ligand. The NCN-Pt group effectively blocks the region about the pyridine nitrogen and thus intramolecular metathesis reactions must take place in opposite hemisphere. This was verified as extension of alkene chain length by one atom had a dramatic effect on the yield of RCM product. After 2 days of reaction with the pyridyl ether system 12, the yield of the RCM product 15a increased to 50\% with the remaining compound found to be isomerized product 15b $(50 \%)$. These results highlight two important factors; both the position and length of the $\alpha$-olefin containing chains are of critical importance to the success of the RCM reaction.

\subsection{Templated synthesis of pyridine-containing macroheterocycles by RCM}

From the monomeric studies, we have shown the nature of the ligand and metal center, as well as the position and chain
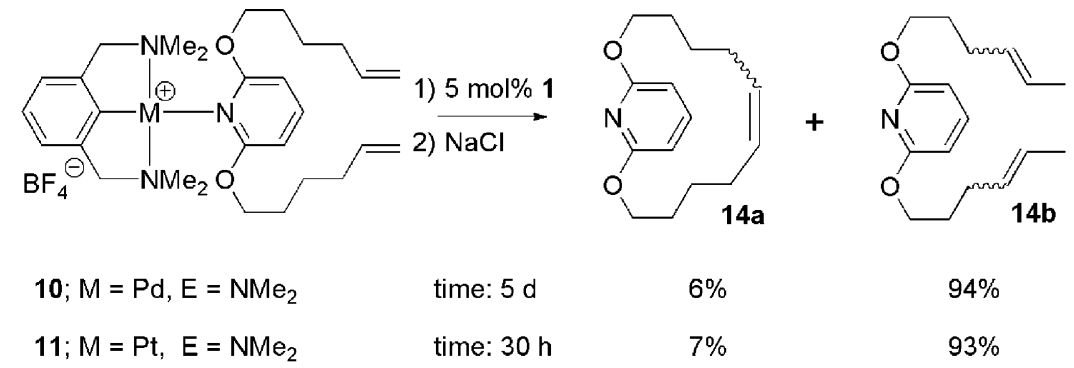

$94 \%$

$7 \%$

$93 \%$
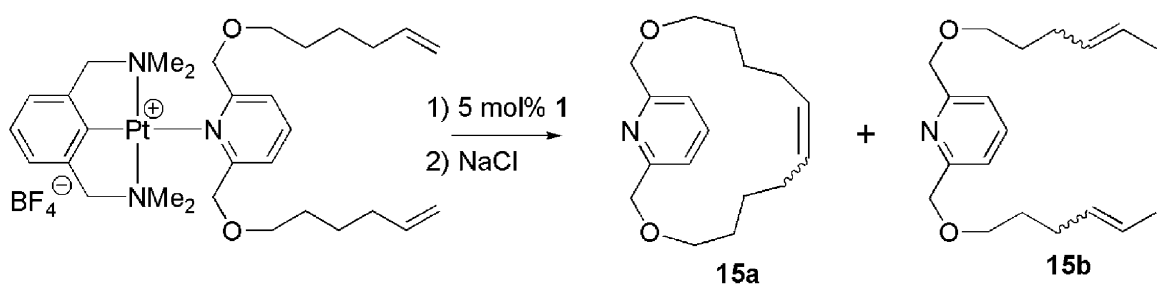

12

time: $48 \mathrm{~h}$

$50 \%$

$50 \%$

Scheme 3. Reactivity of various pincer-metal complexes of 2,6-substituted pyridines. 


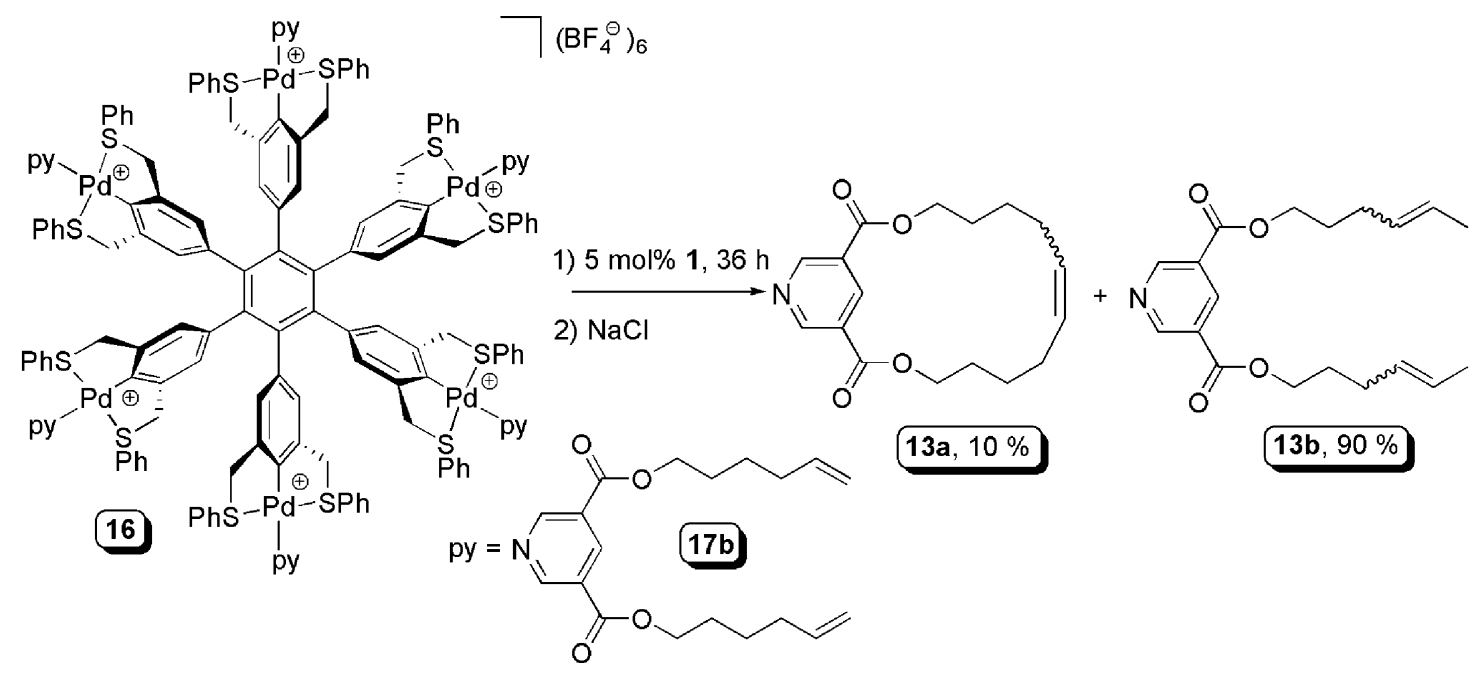

Scheme 4. Attempted formation of a hexakis(pyridine) macroheterocycle.

length of the $\alpha$-olefins, are critically important criteria for the successful application of RCM in these systems. Also, the facile detachment of the pyridine from the pincer-metal complex by reaction with $\mathrm{NaX}$ and the separation of the released pyridine from the reformed pincer-M-X species, two important points for an ideal template, have been demonstrated.

Our initial attempt at templated synthesis of macrocycles involved use of the hexacationic aryl(SCS-Pd-pyridine) 6 com-

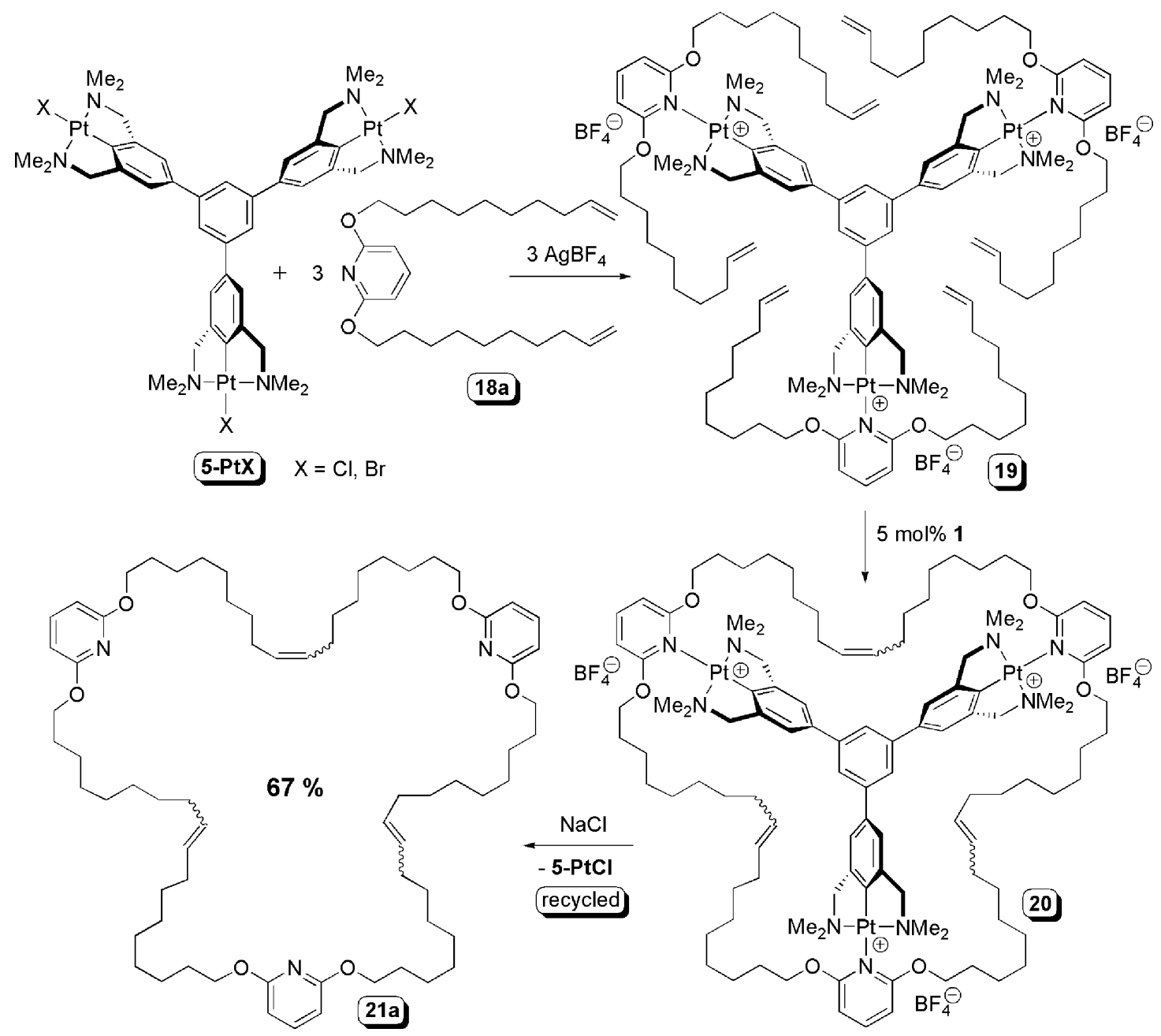

Scheme 5. Synthesis of tris(pyridine) macroheterocycle 21a. 
plex 16 in reaction with first generation Grubbs catalyst $\mathbf{1}$, Scheme 4. Unfortunately, the majority $(90 \%)$ of the pyridine containing product recovered contained isomerized olefins [66]. Additionally, the minor amount of RCM product obtained was exclusively the bicyclic pyridinophane 13a, the same RCM product found using the monomeric systems; no macroheterocyclic products were observed. While the isomerization products were expected as the SCS-Pd motif was employed, the complete lack of higher generation oligomers indicate that 3,5-substitution does not position the $\alpha$-olefins in a favorable orientation for productive generation of macroheterocycles by RCM. Also, the relatively large amount of steric crowding engendered by the hexameric system may also induce pyridine dissociation, thus increasing the potential for olefin isomerization as well as deactivation of the metathesis catalyst by the free pyridines (vide infra) $[18,19]$.

To help alleviate any steric issues and to incorporate the more efficient NCN-Pt motif, a NCN-Pt tripincer template of type 5 was employed. Reaction of three equivalents of 2,6-bis(9decene-1-oxy)pyridine 18a with the trimetallic $\mathrm{C}_{6} \mathrm{H}_{3}$ (NCN-Pt$\mathrm{X})_{3}$ 5-PtX $(\mathrm{X}=$ halide $)$ and 3 eq. $\mathrm{AgBF}_{4}$ quantitatively forms the templated precursor 19, see Scheme 5. Subjecting this complex to RCM with $5 \mathrm{~mol} \%$ of first generation Grubbs catalyst 1 in dilute conditions $(1 \mathrm{mmol} / \mathrm{L})$, followed by decomplexation of the pyridines from the tripincer template with $\mathrm{NaCl}$, afforded the macroheterocycle 21a in $67 \%$ yield as a mixture of cis/trans isomers [64]. Remarkably, this equates to a yield per olefin coupling of $88 \%$; the selectivity for generation of this single product is quite high. The other RCM products, consisting of other oligomers, were separated from the 69-membered ring trimeric macroheterocycle by preparative thin-layer chromatography (TLC). Also, the re-formed tripincer template 5PtX could be separated from 21a and residual Ru species and was essentially quantitatively recycled. Notably, the same batch of (recycled) tripincer was (re)used for all the following reactions described in this section.

Spurred by the success of this reaction, a number of other substituted bis( $\alpha$-olefin) pyridines of type $\mathbf{1 7}$ and $\mathbf{1 8}$, as depicted in Fig. 6, were examined for the RCM synthesis of other macroheterocycles (21b-g) [63,65]. As shown in Scheme 6 and Table 1,3,5-substituted pyridines are not applicable and only the monomeric pyridinophane product $\mathbf{2 2}$ is obtained, Table 1 entry
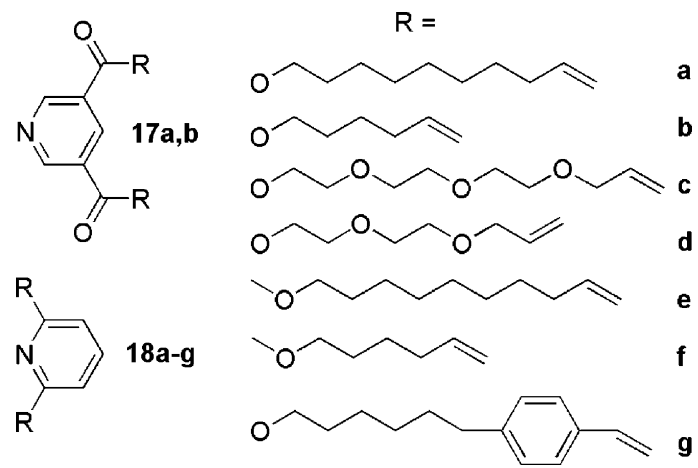

Fig. 6. Various substituted pyridines used in investigations of macroheterocycle formation.

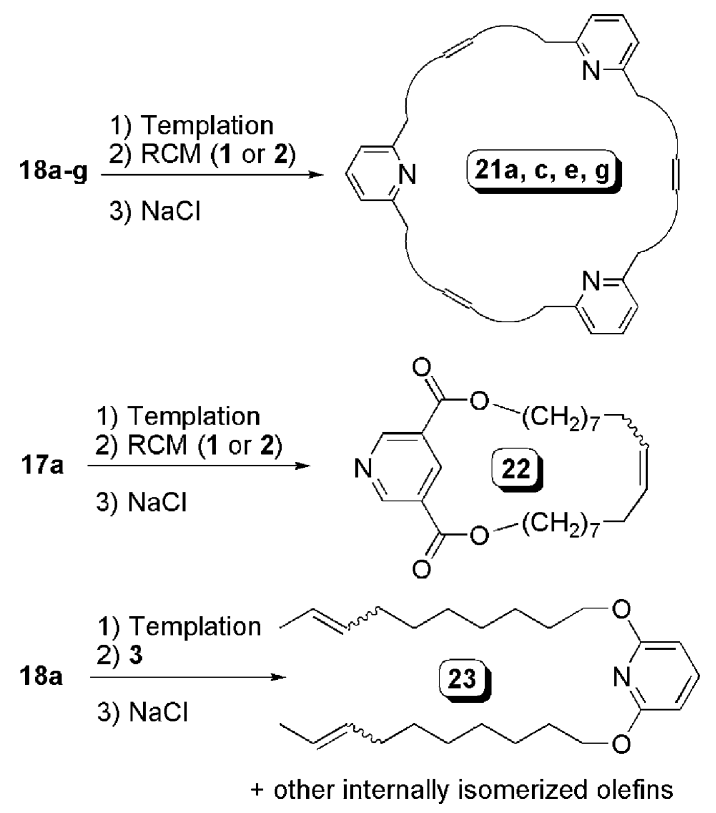

Scheme 6. General templated RCM reactions of pyridines $\mathbf{1 7}$ and $\mathbf{1 8}$

9. In addition, the length of the alkyl chain needs to be of a minimum size for productive metathesis to occur. For example, the 5-hexenyl pyridine $\mathbf{1 8 b}$ is not cyclized and none of the trimeric product is obtained, Table 1, entry 2 , respectively; the "arms" are apparently too short to span the distance across the template to participate in interpyridine metathesis. Extension of the arms compared to 18a has a small effect as well. Elongation of each $\alpha$-olefin chain by inclusion of an additional $\mathrm{CH}_{2}$ group (pyridine 18e) resulted in the generation of a 75-membered macroheterocyclic ring $21 \mathrm{e}$ in $44 \%$ yield, which is still $76 \%$ yield per olefin coupling.

Other types of linkers between the pyridines could also be incorporated into the macroheterocyclic system. A poly(ethylene glycol)-like linker was examined using pyridines 18c and 18d. Again, the system with the shorter length chain (18d, 10 atoms) was ineffective in macroheterocyclization, Table 1, entry 4 . The longer ( 13 atom) chain pyridine $18 c$ generated the corresponding 81-membered ring macroheterocycle 21c in $41 \%$ yield ( $74 \%$ per olefin coupling), generating an interesting pyridine-containing macrocyclic analogue of the well-known

Table 1

Reactivity of pyridines $\mathbf{1 7}$ and $\mathbf{1 8}$ in templated macroheterocycle synthesis

\begin{tabular}{lllllr}
\hline Entry & $\begin{array}{l}\text { Starting } \\
\text { material }\end{array}$ & $\begin{array}{l}\text { Catalyst } \\
\text { (mol\%/pyridine) }\end{array}$ & Time (h) & Product & Yield (\%) \\
\hline 1 & $\mathbf{1 8 a}$ & $\mathbf{1}(5 \mathrm{~mol} \%)$ & 16 & $\mathbf{2 1 a}$ & 67 \\
2 & $\mathbf{1 8 b}$ & $\mathbf{1}(5-10 \mathrm{~mol} \%)$ & $16-74$ & $\mathbf{2 1 b}$ & 0 \\
3 & $\mathbf{1 8 c}$ & $\mathbf{1}(5 \mathrm{~mol} \%)$ & 16 & $\mathbf{2 1 c}$ & 41 \\
4 & $\mathbf{1 8 d}$ & $\mathbf{1}(5-10 \mathrm{~mol} \%)$ & $16-74$ & $\mathbf{2 1 d}$ & 0 \\
5 & $\mathbf{1 8 e}$ & $\mathbf{1}(5 \mathrm{~mol} \%)$ & 16 & $\mathbf{2 1 e}$ & 44 \\
6 & $\mathbf{1 8 e}$ & $\mathbf{2}(5 \mathrm{~mol} \%)$ & 16 & $\mathbf{2 1 e}$ & 20 \\
7 & $\mathbf{1 8 f}$ & $\mathbf{1}(5-10 \mathrm{~mol} \%)$ & $16-74$ & $\mathbf{2 1 f}$ & 0 \\
8 & $\mathbf{1 8 g}$ & $\mathbf{2}(15 \mathrm{~mol} \%)$ & 48 & $\mathbf{2 1 g}$ & 60 \\
9 & $\mathbf{1 7 a}$ & $\mathbf{1}(12.5 \%)$ & 48 & $\mathbf{2 2}$ & 70 \\
10 & $\mathbf{1 8 a}$ & $\mathbf{3}(5 \mathrm{~mol} \%)$ & 16 & $\mathbf{2 3}$ & 67 \\
\hline
\end{tabular}


crown ether family [72,73]. Crown ether pyridinophane complexes have been extensively studied by Vögtle and Newkome [74,75]. In fact, preparation of both corresponding templates, analogues of complex 19 shown in Scheme 5, for the RCM reaction was complicated by retention of a large portion (gravimetrically determined to be $\sim 10 \%$ ) of the by-product Ag salts, formed during the pyridine complexation reaction. The silvercontaining complexes were inactive in RCM, potentially due to metathesis catalyst deactivation, competitive coordination of the olefin with Ag, [76-79] or to effective shortening of the chain by the formation of poly(ether)-Ag complexes [80,81]. Regardless, this necessitated removal of the remaining $\mathrm{Ag}$ salts by reaction with $\mathrm{H}_{2} \mathrm{~S}$ to precipitate the remaining silver as $\mathrm{AgS}$. After elimination of the residual, complexed silver, RCM proceeded normally.

A styrenyl endgroup was introduced into a bis(olefin) pyridine (18g) and, upon templated RCM, generated the 81membered ring stilbene-containing macroheterocycle $\mathbf{2 1 g}$ in $60 \%$ yield ( $84 \%$ per olefin coupling, Table 1, entry 8 ). However, due to the relatively low reactivity of the styrene olefin with 1, [82] a larger quantity (15 mol\%) of the more active second generation Grubbs catalyst 2 needed to be used. No reaction was observed with the first generation catalyst $\mathbf{1}$. Notably, $\mathbf{2 1 g}$ was obtained exclusively in the trans-form but slow isomerization (days) to the cis-form was observed in solution on exposure to sunlight.

Attempts were made to potentially increase the yield of the macroheterocycle $18 \mathrm{e}$ by employing the more active second generation Grubbs catalyst $\mathbf{2}$. However, a steep drop in yield from $44 \%$ with the first generation catalyst to $20 \%$ of the macroheterocycle 21e was observed, Table 1, entries 5 and 6 [64]. In addition, larger quantities of higher generation oligomers were observed, pointing to competitive ring-opening metathesis or cross-metathesis reactions degrading the yield of trimer. In a similar reaction to examine the synthesis of macroheterocycle 21a, Schrock's high oxidation state Mo-based catalyst 3 was employed. In this case, only olefin isomerization was observed (vide infra) with no indication of any RCM products [63].

\subsection{Comments on pathway to macrocycle formation}

While it is tempting to simply assume that coordination and templation of the pyridine pre-organizes the pendant $\alpha$-olefins in a fashion that kinetically favors macrocycle-forming RCM, a number of other factors may be in effect. The olefin metathesis reaction is, in principle, reversible and additional, secondary reactions often occur. Thus, it is often the relative thermodynamic stability of the relevant species in the reaction that governs the eventual product distribution obtained. However, depending on the nature of the reacting olefins, kinetic products can either still participate in further reactions or are trapped and thus preferentially formed. This is elegantly illustrated in a study of cross-metathesis by Grubbs and coworkers and led to a general classification of olefin types with respect to reactivity with a specific catalyst [82]. Type I olefins are quite reactive for formation of homodimeric products and the homodimer products also have significant activity in subsequent metathesis reactions. Type II olefins slowly homodimerize but have significant reactivity towards Type I compounds, generating heterodimeric products. Type III olefins exhibit no homodimerization reaction but still react with Type I species and Type IV olefins are spectators, if present they neither react nor interfere with the ongoing metathesis reaction.

Pertinent to this study is the observation that terminal double bonds are classified as Type I olefins with Grubbs' first generation catalyst $\mathbf{1}$ and, as such, the internal olefin products should display significant secondary metathesis reactivity [83]. To confirm the classification of reactivity between terminal olefins with styrene, a small scale reaction between 1-octene, a suitable mimic of the long chain $\alpha$-olefins in the studied bis(olefin)pyridines, and styrene was performed. In an open atmosphere of $\mathrm{N}_{2}$ with an olefin concentration of $0.2 \mathrm{M}$ and $5 \mathrm{~mol} \% \mathrm{1}$, this cross-metathesis reaction gave 1-phenyl-1-octene as the major product (selectivity $80 \%$ ) with only trace amounts of stilbene after $22 \mathrm{~h}$ at reflux in $\mathrm{CH}_{2} \mathrm{Cl}_{2}$, as expected, Scheme 7. An aliquot of the reaction after $1.5 \mathrm{~h}$ showed a significant concentration of 7-tetradecene by GC-MS, indicating that metathesis of the more reactive terminal alkyl olefins of 1-octene are consumed initially followed by a secondary metathesis of 7-tetradecene with styrene. These results are in accord with Marciniec's investigations on cross-metathesis of vinyl silanes (also a Type I olefin) with styrene [84].

At elevated concentrations, this is also the case here as the pyridinophane formed by RCM of 18a is reactive in secondary ring opening metathesis polymerization (ROMP) in neat conditions catalyzed by $\mathbf{1}$ (vide infra). As such, the trimeric RCM products for macroheterocycle formation, such as $\mathbf{2 0}$, are also

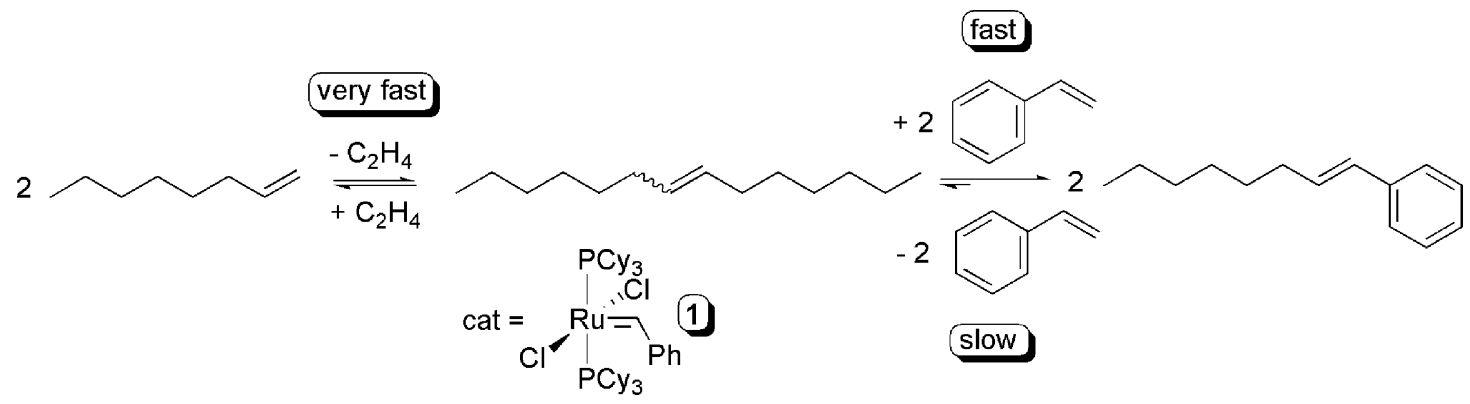

Scheme 7. Cross-metathesis between styrene and 1-octene. 


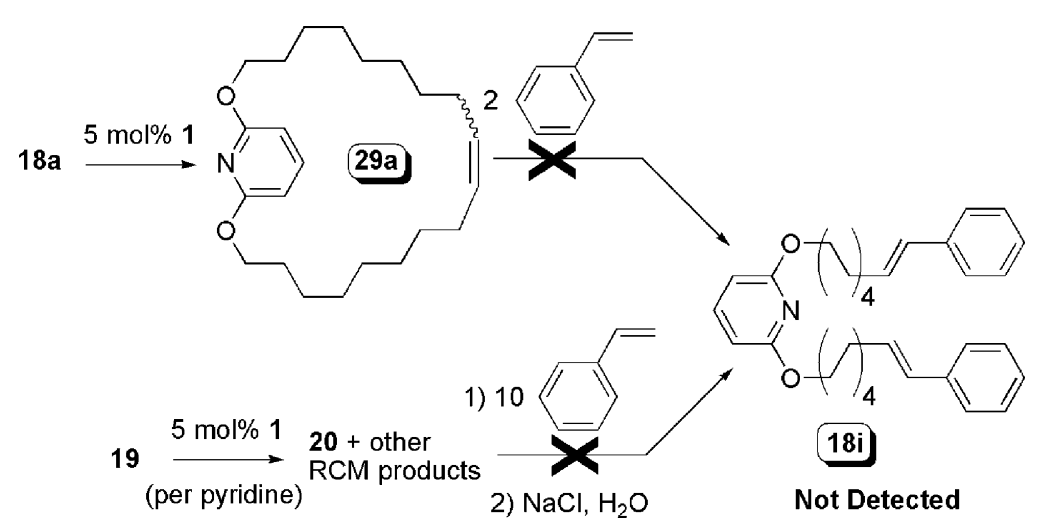

Scheme 8. Attempted formation of styrene capped bis(olefin) pyridine $\mathbf{1 8 i}$.

potentially reactive in further metathesis reactions. However, under similar dilution conditions $\left(10^{-3} \mathrm{M}\right)$ to those of the macroheterocyclization RCM experiments or to the 1-octene/styrene cross-metathesis $(0.2 \mathrm{M})$ reaction, the pyridinophane from 18a does not react over the course of $24 \mathrm{~h}$ with styrene in refluxing $\mathrm{CH}_{2} \mathrm{Cl}_{2}$, Scheme 8. In addition, reaction of the metathesis product mixture from 19 with 10 eq. of styrene does not result in formation of the styrene capped derivative 18i. This indicates that the internal olefins in $\mathbf{2 0}$ are less reactive than those of 7 tetradecene. However, despite the relatively dilute conditions employed (typically $10^{-3} \mathrm{M}$ in complex), some inter-template cross- or ring-opening metathesis may occur, which can account for the higher oligomers formed during RCM. Despite the lack of reactivity with styrene under dilute conditions, these higher oligomers could still be reactive in ROM or cross-metathesis with more reactive olefins.

Due to the effect of incorporation of the tripincer template, the formation of a trimeric macroheterocyclic product is favored by both kinetics and thermodynamics. The three separate olefin metathesis reactions that must occur for successful formation of the macroheterocycle are influenced by the relative orientation and the degrees of freedom associated with dangling $\alpha$-olefin chains $[32,85]$. Kinetically, the formation of pyridinophane products is suppressed by 2,6 substitution pattern of the $\alpha$-olefins on the pyridines. For productive metathesis to occur, the olefins should be approximately organized in a belt about the plane of the central arene core of the tripincer. If the $\alpha$-olefins are forced into this conformation, the yield of macroheterocycle should increase relative to the formation of pyridinophane. Thermodynamically, if any inter-template cross-metathesis has occurred, these products will be entropically disfavored compared to template-macroheterocycle products of type $\mathbf{2 0}$ and the cross- or ring-opening metathesis products will be degraded as the internal olefin is likely still reactive. Due to the greater reactivity of $\mathbf{2}$ versus $\mathbf{1}$, the lowered yield of macroheterocycle 21e observed employing 2 suggests that the rate of secondary cross- or ring-opening metathesis reactions is also an important factor for selective RCM. The greater reactivity of $\mathbf{2}$ may generate higher generation oligomers that are less reactive in further metathesis events, potentially due to entanglement of the olefins within the oligomer structure.

\subsection{Incorporation of steric bulk in the bis(olefin)pyridines}

As the formation of pyridinophane products was noted in the original synthesis, we wanted to limit those products to potentially increase the yield of macroheterocyclization. To explore this, 2,6-bis(dec-9-enyl-1-oxy)-3,5-dimethylpyridine 24a was synthesized, using an analogous method to the other related pyridines, see Scheme 9. A simple ethoxy substituted pyridine 2,6-bis(ethoxy)-3,5-dimethylpyridine $\mathbf{2 4 b}$ was also synthesized. The 3,5 positioning of the methyl substituents should force the pendant $\alpha$-olefins into mutually favorable positions for productive RCM and sterically help prevent pyridinophane formation when attached to the template.

Unfortunately, attempts to complex these hindered pyridines to an $[\mathrm{NCN}-\mathrm{Pt}]^{+}$fragment were not successful, Scheme 10 . Reaction of tripincer 5-PtCl with 3 eq. 24a and 3 eq. $\mathrm{AgBF}_{4}$ in dry $\mathrm{CH}_{2} \mathrm{Cl}_{2}$ resulted in formation of an insoluble precipitate, likely incorporating multiple bridging $[\mathrm{Pt}-\mathrm{X}-\mathrm{Ag}-\mathrm{X}-\mathrm{Pt}]$ interactions, in accord with investigations on the mechanism of halide abstraction in square planar Pt complexes by Ag salts [86]. Attempted reactions of both $\mathbf{2 4 a}$ and $\mathbf{2 4} \mathbf{b}$ with the preformed cation $\left[\mathrm{NCN}-\mathrm{Pt}\left(\mathrm{OH}_{2}\right)\right]\left[\mathrm{BF}_{4}\right] 25$ exhibited no observable displacement of the aqua ligand, even with up to 5 eq. of pyridine. These results were surprising given that the pyridine nitrogen should be inherently more basic than in the unsubstituted versions by inclusion of two electron-releasing methyl groups. However, the reactions show that these pyridines are insufficiently ligating to displace water or even to break up unstable [Pt-X-Ag-X-Pt] aggregates. It appears that by forcing the alkoxy chains forward into the region of the coordinating $\mathrm{N}$ atom, the

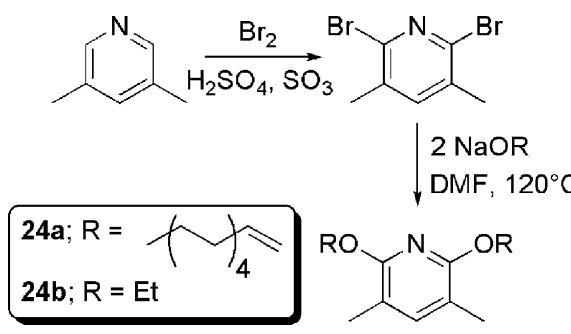

Scheme 9. Synthesis of heavily substituted pyridines $\mathbf{2 4}$. 


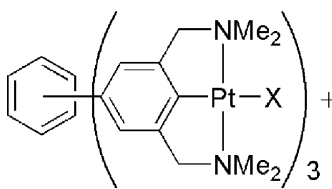

(5)

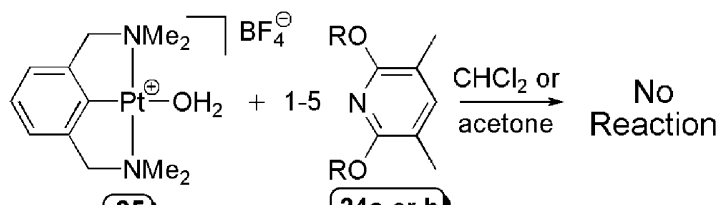

25

$$
\begin{aligned}
& 24 a ; R= \\
& 24 b ; R=E t
\end{aligned}
$$

Scheme 10. Reactivity of heavily substituted pyridines $\mathbf{2 4}$ with NCN-Pt pincers.

steric demand is so great that the pyridine is protected from complexation with the Pt center.

\subsection{Host-guest chemistry}

With usable quantities of macroheterocycles in hand, we set out to explore their reaction chemistry. One potential application is their ability to function as a multi-dentate host molecule for a suitable guest. The initial guest explored was the original tripincer metallo-template 5. To remove any potential complications arising from the presence of cis/trans isomers in the macroheterocycles, compounds 21a, 21c and 21e were hydrogenated

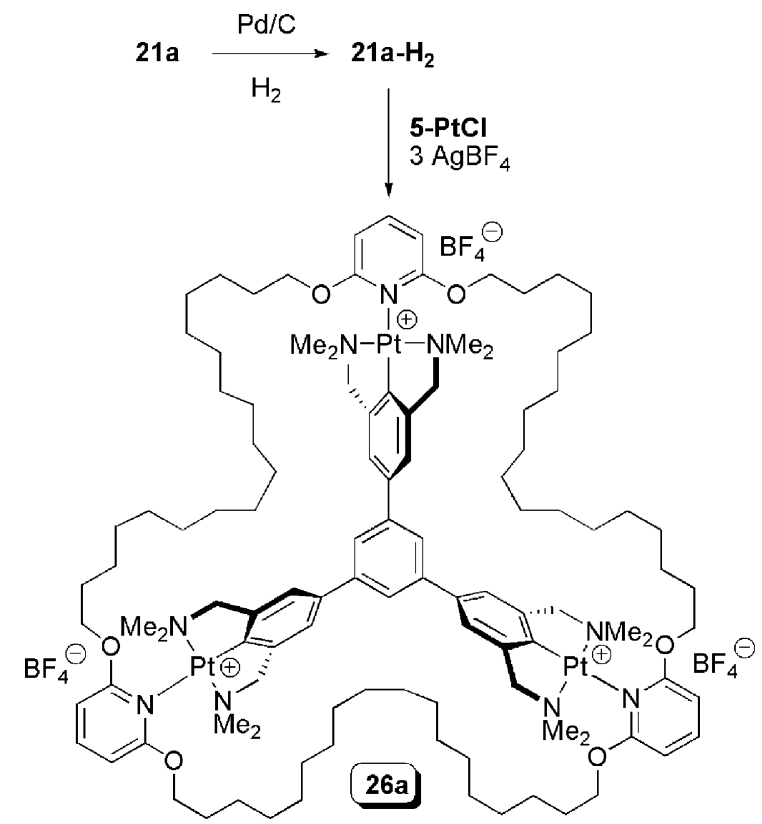

Scheme 11. Example of host-guest macroheterocycle/tripincer complex formation.

using $\mathrm{Pd} / \mathrm{C}$ and $\mathrm{H}_{2}$. Reaction of 5 with 1 eq. of the hydrogenated cycles $\mathbf{2 1}-\mathbf{H}_{2}$ and 3 eq. of $\mathrm{AgBF}_{4}$ generated the corresponding tricationic host-guest compounds $\mathbf{2 6}$, in essentially quantitative yield; the reaction to give 26a is shown in Scheme 11 [63-65]. These complexes were analyzed by NMR spectroscopy, electrospray MS and elemental analysis.

After multiple unsuccessful attempts using the $\mathrm{BF}_{4}$ containing complexes, an X-ray quality crystal of $\mathbf{2 6 a}-\mathbf{B P h}_{\mathbf{4}}$ was

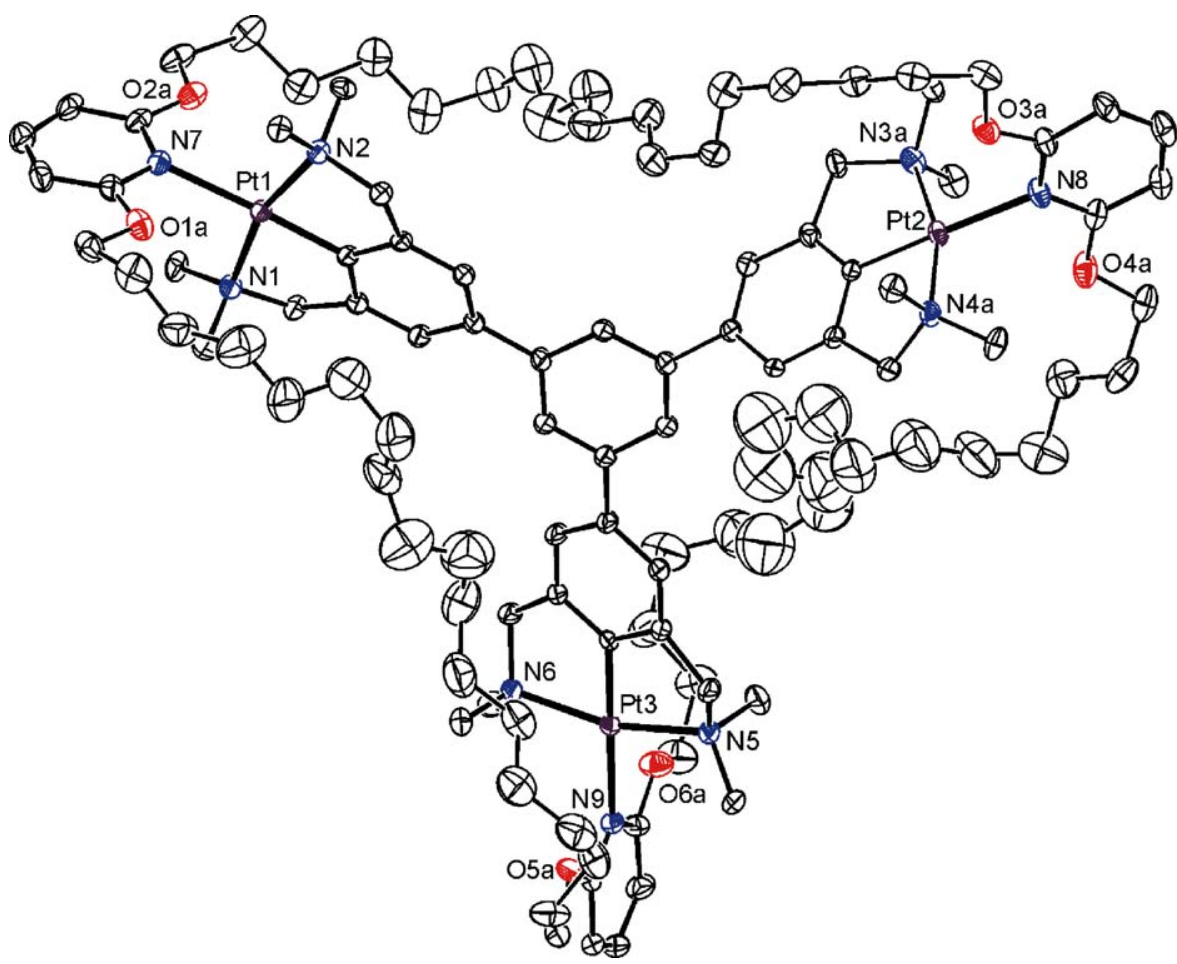

Fig. 7. View of the molecular structure of the trication $\mathbf{2 6 a - B P h}$ in the crystal. Only the major disorder component is shown and displacement ellipsoids at drawn at the $30 \%$ probability level. $\mathrm{H}$-atoms and three $\mathrm{BPh}_{4}$ counteranions have been removed for clarity. See refs. [63,64]. 
obtained from acetone/diethyl ether after exchanging the $\mathrm{BF}_{4}$ anions for the larger tetraphenylborate by reaction with $\mathrm{NaBPh}_{4}$ [64]. A view of the molecular structure of the major disorder component of the trication is shown in Fig. 7. This confirms the re-attachment of the macroheterocycle to the template tripincer suggested by analytical and spectroscopic data and, more importantly, the exclusive 1:1 host to guest ratio in the complex and the perfect cyclic nature of the macroheterocycle. The structure consists of a central arene core that is 1,3,5-trisubstituted with three NCN-Pt groups. The two benzylic- $\mathrm{CH}_{2} \mathrm{NMe}_{2}$ arms are cyclometallated with the Pt center through the arene generating two 5-membered rings per pincer. The fourth coordination site in the square planar geometry about each Pt is occupied by the pyridine of the macroheterocycle and the three pyridines are linked by saturated $\mathrm{O}-\left(\mathrm{CH}_{2}\right)_{18}-\mathrm{O}$ linkages.

For comparison, the structure of a related monomeric NCN-Pt-pyridine complex 27, which contains a 2,6bis(ethoxy)pyridine ligand and a $\mathrm{BF}_{4}^{-}$counteranion, is also presented. This complex was synthesized by simple $\mathrm{AgBF}_{4}$ mediated halide abstraction of $\mathrm{NCN}-\mathrm{PtBr}$ in the presence of the pyridine, see Section 2. A view of the molecular structure of $\mathbf{2 7}$ with selected bond lengths and angles is given in Fig. 8. The Pt center is found within a distorted square planar environment (largest deviation from least squares plane, $0.028(2) \AA$; $\mathrm{C} 1$ ). The Pt-N distances for the amino arms are typical (Pt1-N 12.0815(17); Pt1-N2 2.0898(17) $\AA$ ) as is the Pt-pyridine $\mathrm{N}$ bond $(2.1730(16) \AA$ ). The pyridine is coordinated through the Pt center and is essentially perpendicular to the pincer arene ring (twist angle $83.98(11)^{\circ}$ ) and to the square planar NCN-Pt core (twist angle $83.30(11)^{\circ}$ ). However, the pyridine ring lies somewhat unsymmetrically within the pincer pocket and is decidedly tipped towards $\mathrm{N} 2$; the (pseudo) bond angle between Pt1-N3-C15 is $170.93(7)^{\circ}$. All other bond lengths and angles are similar to those in other NCN-Pt complexes $[51,87,88]$ and to those for the NCN-Pt-pyridine groups in $\mathbf{2 6 a - B P h}$.

Complexation of the macroheterocycle has induced some distortions in the tripincer portion of $\mathbf{2 6 a}-\mathbf{B P h} \mathbf{h}_{\mathbf{4}}$ with respect to the uncomplexed molecule. Structural determination of the platinum chloride (5-PtCl) [63] and palladium bromide (5-PdBr) [59] shows that both molecules crystallize with perfect $D_{3 \mathrm{~h}}$ symmetry. In 5-PtCl, the twist angle between central benzene and

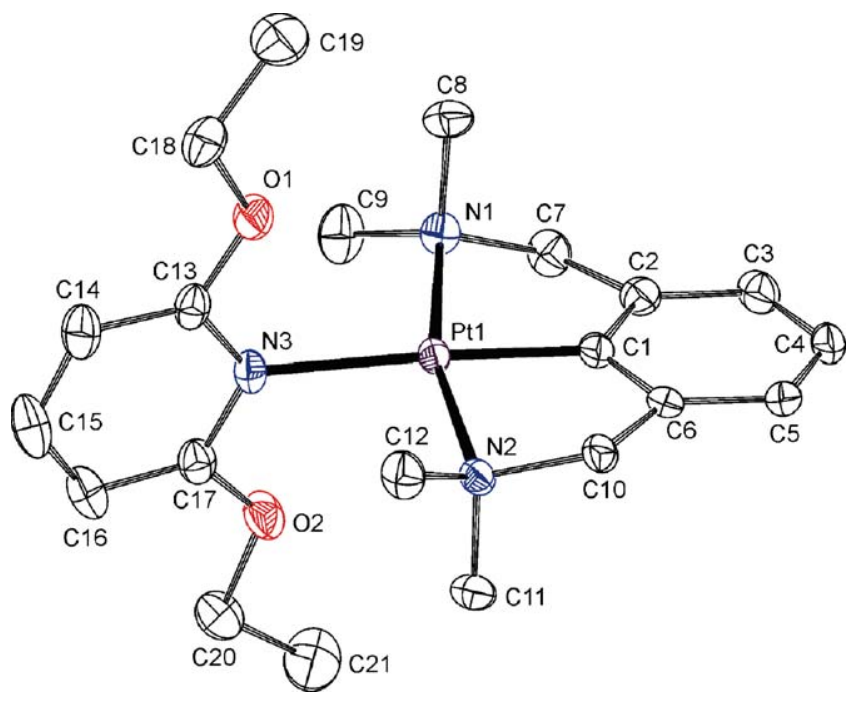

Fig. 8. View of the cation in the molecular structure of $\mathbf{2 7}$ in the crystal with displacement ellipsoids at the $50 \%$ probability level. H-atoms and the $\mathrm{BF}_{4}$ counteranion have been removed for clarity. Selected bond lengths ( $\AA$ ) angles and torsion angles $\left({ }^{\circ}\right)$ : C1-Pt1 1.9158(19), N1-Pt1 2.0815(17), N2-Pt1 2.0898(17), N3-Pt1 2.1730(16), C1-Pt1-N1 81.86(8), C1-Pt1-N2 82.00(8), C1Pt1-N3 177.05(8), C1-C2-C7-N1 25.1(2), C1-C6-C10-N2 22.2(2).

the plane of all three pincer arenes is $40.2(2)^{\circ}$. The equivalent angle in $\mathbf{5 - P d B r}$ is $47.31^{\circ}$. Complexation of the macroheterocycle results in lowering of the molecular symmetry and significant distortions in the central arene-pincer arene twist angles. The twist angles between the core and the NCN pincer arenes containing Pt 1 and $\mathrm{Pt} 3$ were greatly reduced to $25.7(3)$ and $28.2(3)^{\circ}$, respectively. The NCN pincer ligated to $\mathrm{Pt} 2$ was disordered (two site, occupancy of major isomer, 65.5\%) and the major and minor components exhibited twist angles of 55.5(3) and $85.1(5)^{\circ}$, respectively. Two of the pincers are distorted towards co-planarity with the core while one is more orthogonal. In addition, the pyridine rings are more perpendicular to the NCN-Pt plane, with twist angles ranging between $84.3(4)$ and $89.9(3)^{\circ}$. The twist angle in $\mathbf{2 7}$ is $83.30(11)^{\circ}$. Also, as in $\mathbf{2 7}$, the pyridine rings are not symmetrical bound with regard to the pincer ligand and exhibit Pt- $\mathrm{N}_{\text {pyridine }}-\mathrm{C}_{\text {para-pyridine }}$ angles of 161.2(3), 171.4(3) and $178.2(3)^{\circ}$ for pyridines ligated to Pt1, Pt2 and Pt3, respectively. The equivalent angle in 27 is $170.93(7)^{\circ}$.
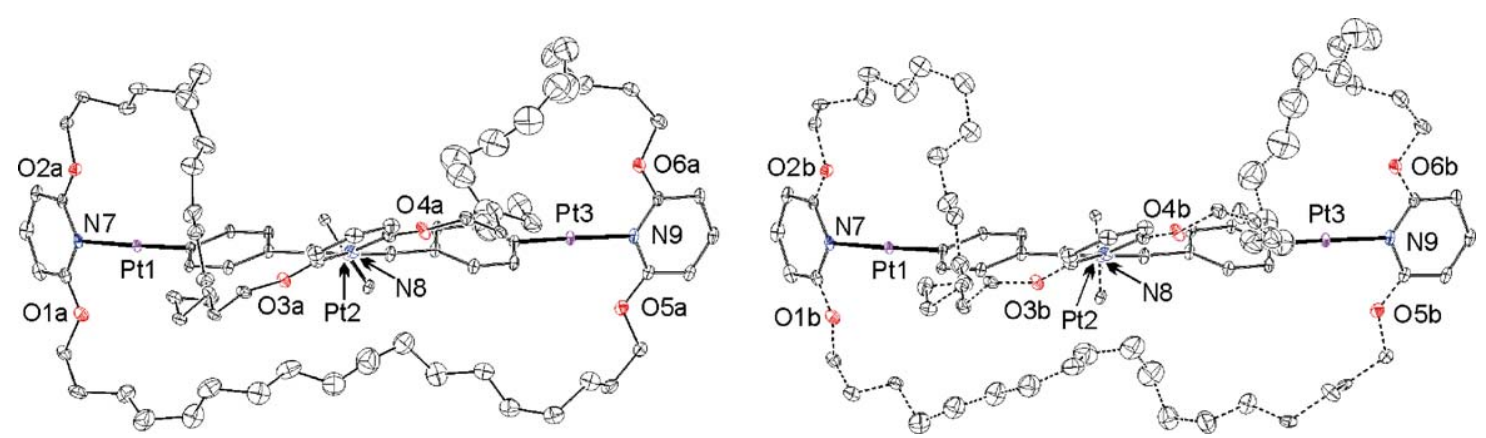

Fig. 9. Side view of molecular structure of the major (left) and minor (right) disorder components of $\mathbf{2 6 a - B P h}$. Displacement ellipsoids are drawn at the 10\% probability level and $\mathrm{H}$-atoms, $\mathrm{CH}_{2} \mathrm{NMe}_{2}$ groups and $\mathrm{BPh}_{4}$ counteranions are removed for clarity. 
These distortions are likely a result of strain imposed by the linking $\mathrm{O}-\left(\mathrm{CH}_{2}\right)_{18}-\mathrm{O}$ chains connecting the pyridines in the macroheterocycle. As shown in Fig. 9, the link terminating with $\mathrm{O} 1$ and $\mathrm{O} 5$ is below the plane of the core arene (as drawn). The other two chains have termini where one is above the core and the other is almost co-planar with the central benzene. The connector containing $\mathrm{O} 4$ and $\mathrm{O} 6$ is exclusively above the core while the link containing $\mathrm{O} 2$ and $\mathrm{O} 3$ actually crosses the plane defined by the central benzene. This geometry is most probably the result of the size of the linking chain. It appears that the distance between the Pt centers in the tripincer is slightly too small to perfectly accommodate the 69-member ring of the macroheterocycle. In 5-PtCl, the $\mathrm{Cl}-\mathrm{Cl}$ separation is 17.281(2) $\AA$ while in $\mathbf{5 - P d B r}$, the $\mathrm{Br}-\mathrm{Br}$ distance is 17.4573(4) $\AA$. The heterocycle is puckered above and below the plane of the tripincer to generate more space for the alkoxy chains and also demonstrates the conformational flexibility of the macroheterocycle. The observed orientation of the linked pyridines is the cause of the acute twist angles found between the tripincer core and NCN pincers containing Pt1 and Pt3. Notably, the NCN-Pt2 pincer, which is complexed to the pyridine with oxygen's of the alkoxy chains in the same plane as the core (O3 and $\mathrm{O} 4)$, exhibits the widest central arene/NCN arene twist angle.

In addition, other scaffolds were found to act as guests for the trimeric heterocyclic host. A phenylene extended tripincer 6-PtCl can be complexed by the smallest macroheterocycle 21a$\mathbf{H}_{\mathbf{2}}$ to generate 28, Fig. 10, as indicated by NMR spectroscopy. While crystals have yet to be obtained, a calculated structure (molecular mechanics, Spartan) indicates that the alkoxy linkers are quite elongated, indicating that the $\mathrm{M}-\mathrm{M}$ separation here is perhaps the limit for formation of a discrete host-guest complex. However, this does show that there is a fair degree of flexibility associated with formation of these host-guest complexes and that the macrocyclic host can accommodate guests of differing size. The calculated structure of $\mathbf{6 - P t B r}$ exhibits $\mathrm{Br}-\mathrm{Br}$ distances of $24.6 \AA$ [58], significantly $(\sim 7 \AA)$ longer than those obtained from the X-ray crystal structure of the simple tripincers 5-PtCl and $5-\mathbf{P d B r}$, giving a potential bound for the size of guests that macroheterocycle 21a can encircle.

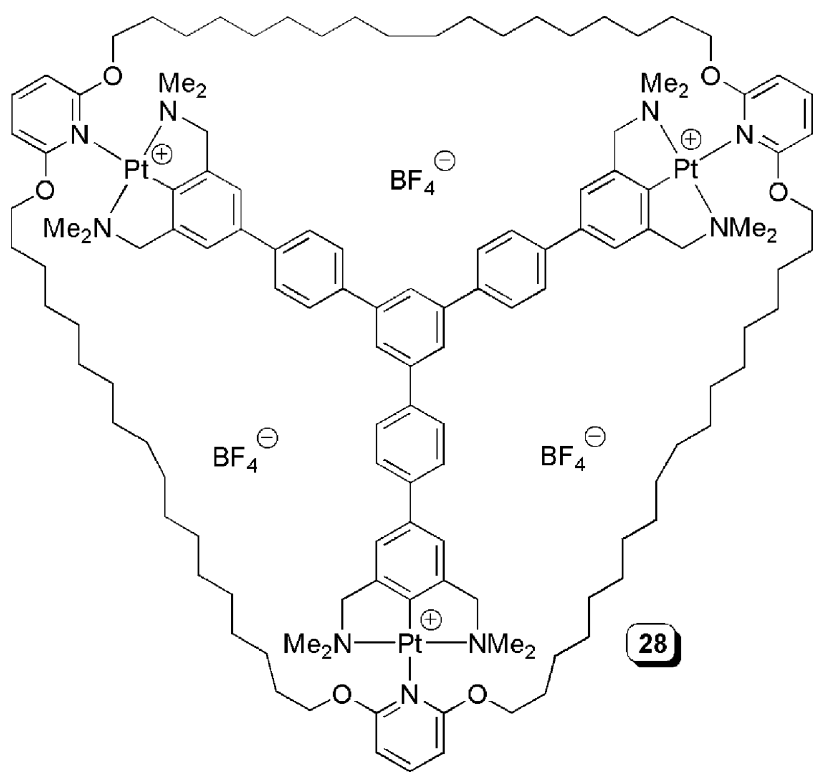

Fig. 10. Structure of host-guest complex incorporating tripincer 28.

\subsection{Olefin isomerization}

Isomerization of terminal $\alpha$-olefins to the thermodynamically more stable internal alkenes is an unwanted side reaction that occasionally accompanies olefin metathesis [89-95]. Recent results point to, in the case of the Ru-based systems, binuclear $\mathrm{Ru}-\mathrm{H}$ catalyst decomposition products that form during the reaction as the species that catalyze olefin isomerization. A recent report by Grubbs has identified the structure of a thermal decomposition product, a bridged $\mathrm{Ru}_{2}$-carbide hydride, that is also an active isomerization catalysts [96]. In some instances, the more active $N$-heterocyclic carbene $\mathrm{Ru}$ complexes, such as $\mathbf{2}$, show a greater propensity for isomerization activity than the original $\mathrm{P}(\mathrm{Cy})_{3}$ system 1 [97]. The Mo-based catalysts of Schrock, such as $\mathbf{3}$, are only rarely reported to be involved in this type of reactivity $[98,99]$.

We have also observed olefin isomerization in a number of reactions, notably with the less side reaction prone first gener-
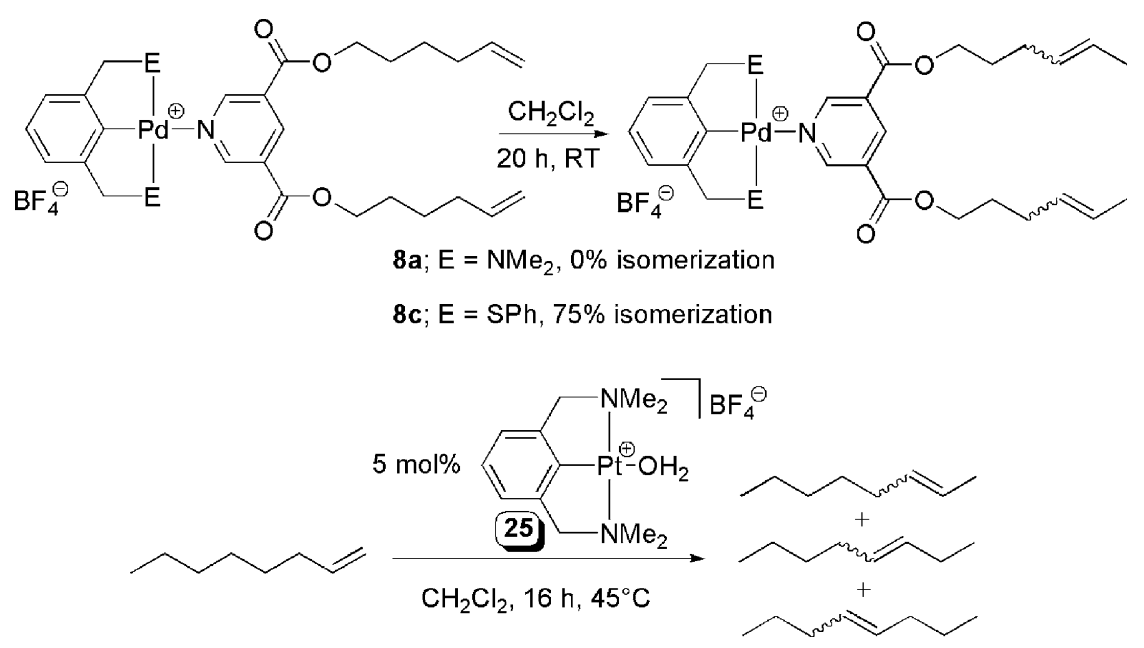

Scheme 12. Olefin isomerization with Pd and Pt pincer complexes. 
ation Grubbs catalyst $\mathbf{1}$ and Mo-based Schrock system 3. The question is: what is the active isomerization catalyst in these cases? Either it is proceeding via the normal route, i.e. catalyzed by metathesis catalyst decomposition products, or the pincer complexes may not be innocent. Independent reactions have shown that pincer Pt or Pd cationic complexes are quite active for this transformation. Stirring of the monomeric SCSPd-pyridine complex $8 \mathbf{c}$ at room temperature in $\mathrm{CH}_{2} \mathrm{Cl}_{2}$ in the absence of a metathesis catalyst gave $75 \%$ isomerization of the olefins after $20 \mathrm{~h}$, see Scheme 12. In contrast, the analogous NCN-Pd-pyridine complex $8 \mathbf{a}$ was inactive over the same period [66].

Replacement of the strongly coordinating pyridine with a weaker base, $\mathrm{H}_{2} \mathrm{O}$, provides an effective pincer-based isomerization catalyst as well. A catalytic quantity $(5 \mathrm{~mol} \%)$ of the NCN-Pt aqua complex 25 was reacted with 1-octene in $\mathrm{CD}_{2} \mathrm{Cl}_{2}$ at $45{ }^{\circ} \mathrm{C}$ for $16 \mathrm{~h}$. Quantitative conversion to multiple internally isomerized octene products was observed by ${ }^{1} \mathrm{H}$ NMR spectroscopy and is depicted in Scheme 12. These results point to the reason why NCN-Pt-bis(olefin) pyridine complexes are the best substrates for the RCM reaction. Thus, in addition to providing a well-defined, stable template, the strength of the metal-pyridine bond appears to be of utmost importance to suppress the isomerization activity of the metallopincer system.

The relative strength of the Pd-pyridine versus Pt-pyridine bond and, by corollary, the failure of the NCN-Pd-pyridine complex 8a in selective RCM, is illustrated by a competition experiment. As shown in Scheme 13, reaction of [NCN-Pt$\left.\left(\mathrm{OH}_{2}\right)\right]\left[\mathrm{BF}_{4}\right]$ with [NCN-Pd-(4-picoline)][BF $]$ results in complete exchange of the aqua and 4-picoline ligands [66]. This demonstrates that the Pt-N bond to 4-picoline is much stronger than the equivalent Pd-N bond; the water ligand in either the $\mathrm{Pd}$ or Pt complexes is relatively weakly bound is efficiently displaced by 4-picoline. This also helps to explain the differences in reactivity of the NCN-, PCP- and SCS-Pd-pyridine triad. In a related study, a competition experiment between aryl PCP-Pd and perfluoroaryl PCP-Pd complexes for pyridine demonstrates that changes in the electron donating ability of the coordinating atom of the pincer can electronically influence the bonding of a labile base [100]. As the $\left(\mathrm{C}_{6} \mathrm{~F}_{5}\right)_{2} \mathrm{P}$ groups are poor $\sigma$-donors but relatively good $\pi$-acceptors, the Pd center is electron deficient compared to the phenyl PCP system and thus preferentially complexes the strong pyridine base. Here, the amino nitrogens are less effective donors that either phosphine or thioethers [101]. As such, the Pd is somewhat more electron-deficient in the NCN case and thus forms a stronger dative bond to the pyridine ligand which prevents olefin coordination and curbs isomerization activity.

While we have not explored detailed mechanistic studies, it is clear that the ECE-Pd or Pt framework generates a compe-

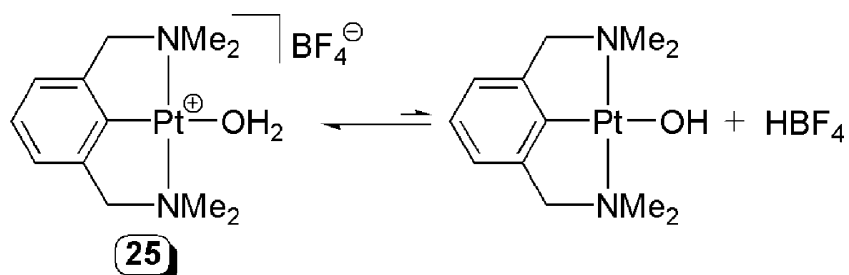

Scheme 14. Production of acidic protons from 25

tent olefin isomerization catalyst. One possible pathway assumes that either the pyridine or aqua ligand is replaced by the olefin to form a transient "pincer-M-olefin" complex from which the isomerization reactions occur. A number of noble metal catalysts perform this reaction [102]. However, the bound ethylene in this complex is likely very labile due to the strong trans effect of the aryl group and thus easily displaced by other Lewis basic ligands. Alternately, an acid catalyzed mechanism may be in operation [102]. Complexation of water to a Lewis acid greatly increases the Brønsted acidity of the O-bound protons. For example, the $\mathrm{p} K_{a}$ of the water adduct of highly Lewis acidic $\mathrm{B}\left(\mathrm{C}_{6} \mathrm{~F}_{5}\right)_{3}$ was calculated to be 8.4 in acetonitrile, essentially identical to $\mathrm{HCl}\left(\mathrm{p} K_{a}=8.5\right)$ in the same solvent [103]. In this case, the aqua adduct $\mathbf{2 5}$ may simply be acting as a source of protons by the equilibrium shown in Scheme 14. Traces of water in the reaction of pyridine complex $8 \mathbf{c}$ are a possible source of protons in that case. Nevertheless, while additional investigations are needed to unravel this problem, the strength of the M-py bond would be key in suppressing olefin isomerization by preventing formation of catalytically active species proposed in either mechanism.

With Schrock's catalyst 3, it is probable that the NCN-Pt species is also the culprit for the olefin isomerization observed [63]. The high oxidation state Mo center is much more electrophilic than the Ru centers in the Grubbs-type catalysts. As such, it is generally more sensitive toward Lewis basic impurities. The fact that no RCM or other metathesis products were observed here is also of note, as the Mo catalysts are efficient for the metathesis of internal olefins [5], so the nature of the catalyst must have been altered. All the NCN-Pt-pyridine complexes studied in the context of RCM are cationic and contain complimentary $\mathrm{BF}_{4}$ counteranions. These can potentially disproportionate to give $\mathrm{BF}_{3}$ and $\mathrm{F}^{-}$, especially if a fluoride acceptor is present. However, excesses of up to 5 eq. of $\left[\mathrm{NBu}_{4}\right]\left[\mathrm{BF}_{4}\right]$ did not interact with the Mo catalyst by NMR experiments, precluding reaction with the counteranion as the source of altered reactivity. In addition, pyridines are known to complex to the Mo catalysts rendering them inactive for olefin metathesis [5]. In fact, ${ }^{1} \mathrm{H}$ NMR spectra of monomeric NCN-Pt-pyridine complexes of type $\mathbf{1 1}$ and $\mathbf{1 2}$ as well as trimeric systems 19 in wet acetone- $\mathrm{d}_{6}$ or $\mathrm{CD}_{2} \mathrm{Cl}_{2}$ exhibit small peaks for the free pyridine, indicating

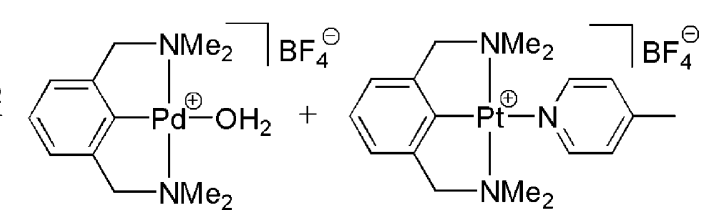

Scheme 13. Competition experiment for 4-picoline between NCN-Pd and NCN-Pt pincers. 


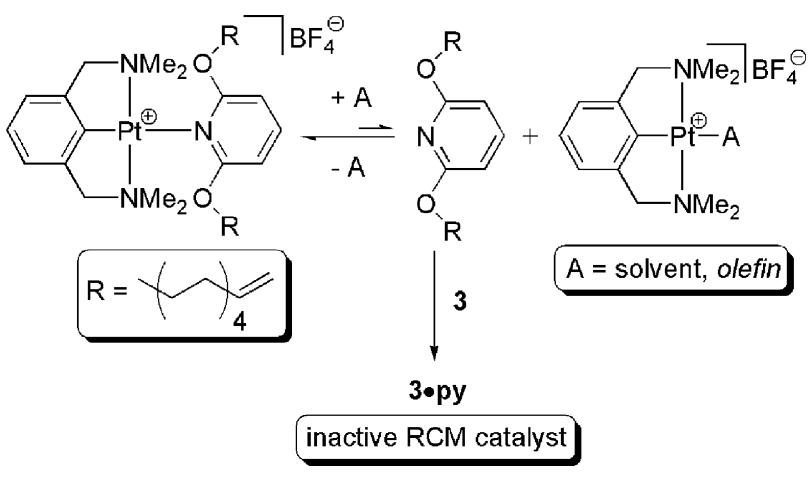

Scheme 15. General reaction sequence for RCM catalyst deactivation and olefin isomerization.

that, even in the NCN-Pt system, the pyridine base is somewhat labile. Based on this, a similar situation to the $\mathrm{Ru}$ systems is likely, involving coordination of a pyridine to the metathesis catalyst which opens a site at either Pt or Pd for olefin or water coordination and subsequent isomerization. Pyridine coordination also acts to suppress the catalyst activity of $\mathbf{3}$, explaining the lack of any RCM products. A general reaction sequence is shown in Scheme 15. Also, as $\mathbf{3}$ is highly reactive towards traces of water, this possibly points to the metal catalyzed pathway as the mechanism of isomerization.

\subsection{NCN-Pt pincers as protecting groups and RCM with unprotected bis( $\alpha$-olefin) substituted pyridines}

One interesting potential application for the NCN-Pt motif is its use as a pyridine protecting group. As both the silvermediated attachment of the pyridine to $\mathrm{Pt}$ and the release of the pyridine by reaction with $\mathrm{NaCl}$ are quantitative reactions, plus the fact that NCN-PtCl byproduct is recyclable, this is a potentially useful and practical methodology.

Reaction of the first generation Grubbs catalyst 1 with NCNPt complexed 3,5-disubstituted pyridine 9 results in quantitative $\mathrm{RCM}$ at reflux in $\mathrm{CH}_{2} \mathrm{Cl}_{2}$ in $2 \mathrm{~h}$, Scheme 2. The bis(decenyl) pincer ligated derivative also reacted under similar conditions, resulting in pyridinocyclophane $\mathbf{2 2}$. However, attempts to react the unprotected pyridine in RCM with 1 showed only $\sim 20 \%$ conversion after $16 \mathrm{~h}$, see Scheme 16 ; the pyridine nitrogen is competing effectively for the olefin coordination site and suppressing catalyst activity. In contrast, 2,6 substitution on the pyridine in the protected systems 10-12 led to significant amounts of olefin isomerization when RCM was attempted with

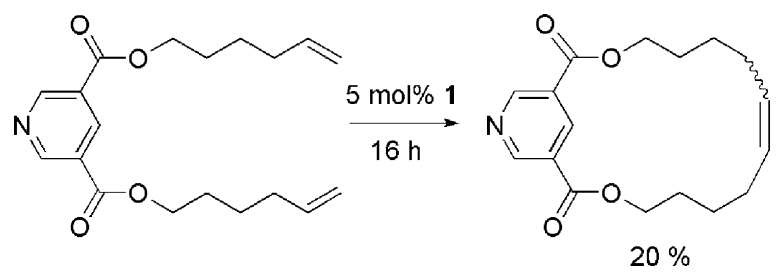

Scheme 16. RCM with an unprotected 3,5-disubstituted pyridine.

1, Scheme 3. Surprisingly, in the unprotected case, reaction of 1-decenyl pyridine 18a with 1 under RCM conditions resulted in quantitative formation of the pyridinocyclophane product 29a in less than $10 \mathrm{~min}$ in refluxing $\mathrm{CH}_{2} \mathrm{Cl}_{2}$, Scheme 17. As expected, the heavily substituted, and difficult to coordinate, 2,6-bis $(\alpha-$ olefin)-3,5-dimethyl pyridine $\mathbf{2 4 a}$ also reacts to generate $\mathbf{2 9 b}$ in a similar time frame. Removal of the solvent and further reaction generates an insoluble solid, which is presumably the ROMP polymer product 30, of which there may be a number of isomers [95]. Similar Lewis base containing poly(thiophene)polyethylene block co-polymers, synthesized by metathesis, have recently been reported [104]. Attempts to perform the same reaction with the Schrock catalyst 3 under the same conditions (5 mol\%) showed no reaction with either $\mathbf{1 8 a}$ or $\mathbf{2 4 a}$ over $16 \mathrm{~h}$; raising the concentration of catalyst to $20 \mathrm{~mol} \%$ results in $67 \%$ RCM with 18a with $20 \%$ starting material, $13 \%$ of an unidentified species ( ${ }^{1} \mathrm{H}$ NMR) and, in line with most previous studies, no olefin isomerization products. The high electrophilicity of $\mathbf{3}$ is apparently much more sensitive to the Lewis basic pyridines studied here than $\mathbf{1}$.

\subsection{Alternate templates, pincer-porphyrin hybrids}

Due to the success of the tripincer complexes in the synthesis of macroheterocycles, alternate templates may also exist that allow for the generation of new macroheterocyclic products. One potential system for the synthesis of a tetrameric macroheterocycle are pincer porphyrin hybrids, species which incorporate four pincer functionalities regularly substituted about a porphyrinic core [105]. Preliminary results using pyridine 18a indicate that a NCN-Pt substituted Ni-porphyrin is suitable for the formation of a 92 membered macroheterocycle containing four pyridine units, Fig. 11 [106]. On a small scale, the porphyrin can be efficiently recycled $(97 \%)$ and the tetramer is obtained in $\sim 50 \%$ yield. This result points to the potential generality of this strategy for macrocycle synthesis.

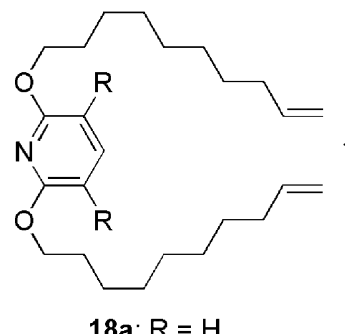

$18 a ; R=H$

24a; $R=M e$

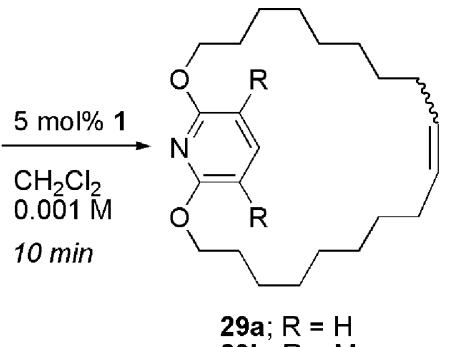

29b; $\mathrm{R}=\mathrm{Me}$

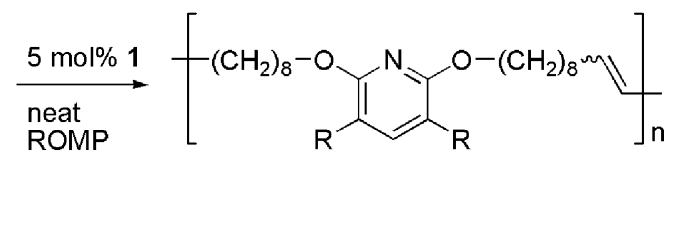

$30 \mathrm{a} ; \mathrm{R}=\mathrm{H}$

30b; $\mathrm{R}=\mathrm{Me}$

Scheme 17. RCM and ROMP with unprotected 2,6-disubstituted pyridines 18a and 24a. 

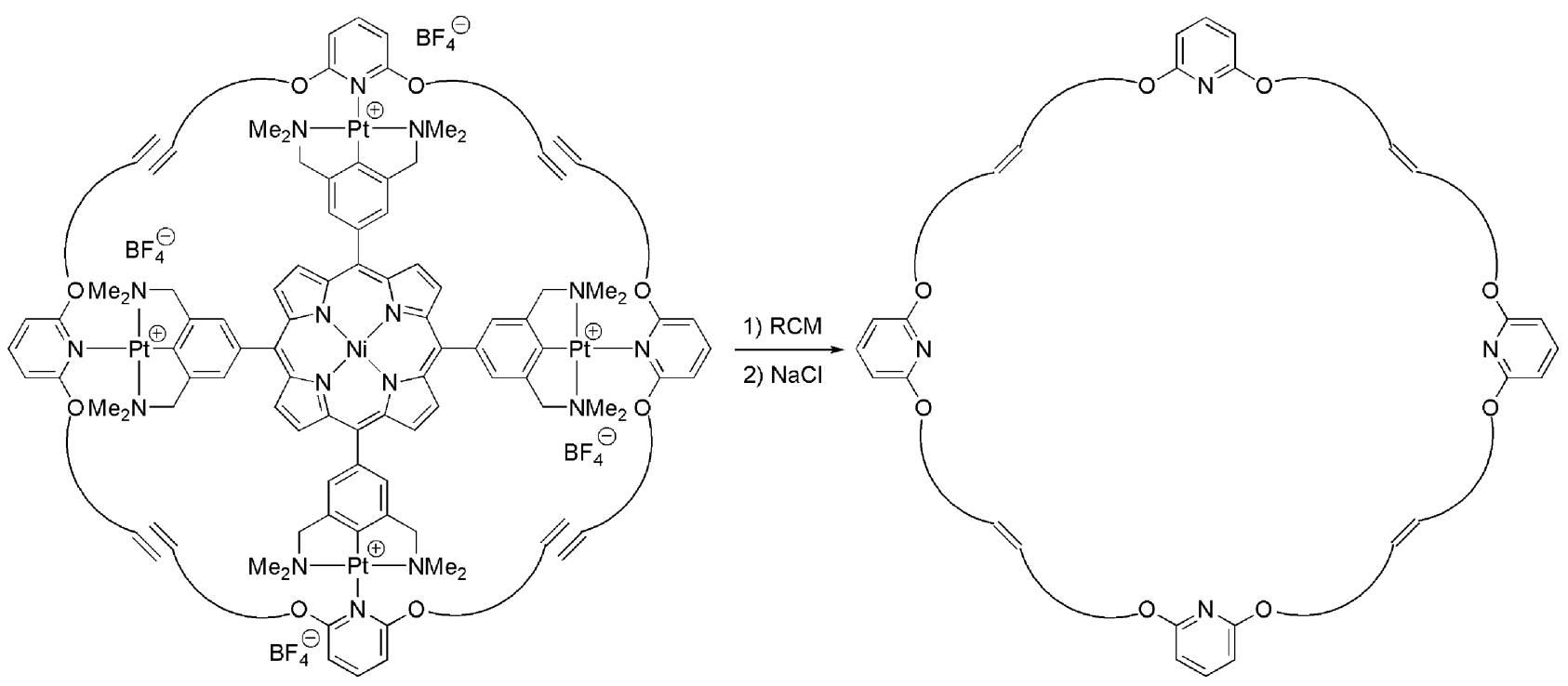

Fig. 11. Structure of alternate pincer-porphyrin template.

\section{Conclusions}

Templation via coordination of substituted pyridines to multimetallic pincer complexes is a versatile method for the RCM generation of a number of macroheterocycles in good to excellent yields. Studies with a variety of Pd- and Pt-based monomeric pincer systems showed that the NCN-Pt motif was superior in that metathesis was rapid and the formation of by-products, namely olefin isomerization products, was limited. These studies also demonstrated that the substitution pattern of the $\alpha$-olefins on the pyridine ring and the length of the olefinic chains are important parameters to consider.

While preliminary investigations with a hexameric SCS-Pd system were not successful, fulfillment of the initial goals of the project were realized utilizing a trimeric NCN-Pt system with a planar, benzene core. A number of trispyridine macroheterocycles were obtained in yields of up to $67 \%$ and the trispincer templates were efficiently recycled. Hydrogenated macrocycles were then employed in host-guest chemistry, where the X-ray crystal structure of one example provided clear evidence for the 1:1 host to guest ratio in the complex and the perfect cyclic nature of the macroheterocycle. Further studies also showed that other, extended guests can be accommodated.

The side reaction of olefin isomerization and the utility of the pincer functionality as a protecting group were also studied. First, it was apparent that both pincer Pd and Pt complexes are competent isomerization catalysts, although the exact mechanism is unclear. However, the strength of the pyridine-metal bond appears to be of utmost importance for both efficient templation and suppression of isomerization under RCM conditions. Complexation of the Lewis basic pyridine nitrogen to the metal center was important to have productive RCM for 3,5-disubstitution of the $\alpha$-olefins on the pyridine ring; the cationic pincer metal unit acts as a protecting group. Conversely, this protection was unnecessary for 2,6-disubstituted pyridines and rapid RCM was noted with these olefins under dilute conditions.
Finally, the generality of this templation methodology was demonstrated by the use of a tetrakis-metallopincer metalloporphyrin hybrid. This expands the potential utility of this method to the synthesis of other macroheterocyclic products.

\section{Acknowledgements}

P.A.C. thanks the Natural Sciences and Engineering Research Council of Canada (NSERC) for a postdoctoral fellowship. The work herein was supported by the Netherlands Research School Combination Catalysis (NRSC-C) (G.P.M.v.K), the Council for Chemical Sciences of the Netherlands Organization for Scientific Research (CW-NWO) (M.L. and A.L.S.), jointly by the NWO (Netherlands) and RFBR (Russia), international grant \# 047.015.005 (G.P.M.v.K) and Utrecht University (P.A.C).

\section{References}

[1] R.H. Grubbs (Ed.), Handbook of Metathesis, Wiley-VCH, Weinheim, 2003.

[2] R.H. Grubbs, Tetrahedron 60 (2004) 7117-7140.

[3] T.M. Trnka, R.H. Grubbs, Acc. Chem. Res. 34 (2001) 18-29.

[4] R.H. Grubbs, S. Chang, Tetrahedron 54 (1998) 4413-4450.

[5] R.R. Schrock, A.H. Hoveyda, Angew. Chem. Int. Ed. 42 (2003) $4592-4633$.

[6] S.J. Connon, S. Blechert, Angew. Chem. Int. Ed. 42 (2003) 19001923.

[7] A. Fürstner, Angew. Chem. Int. Ed. 39 (2000) 3013-3043.

[8] K.C. Nicolaou, P.G. Bulger, D. Sarlah, Angew. Chem. Int. Ed. 44 (2005) 4490-4527.

[9] A. Fürstner, A. Leitner, Angew. Chem. Int. Ed. 42 (2003) 308-311.

[10] K.J. Ivin, J.C. Mol, Olefin Metathesis and Metathesis Polymerization, Academic Press, London, 1997.

[11] P.E. Romero, W.E. Piers, Angew. Chem. Int. Ed. 43 (2004) 6161-6165.

[12] S. Rigaut, D. Touchard, P.H. Dixneuf, Coord. Chem. Rev. 248 (2004) $1585-1601$.

[13] A. Fürstner, M. Liebl, C.W. Lehmann, M. Picquet, R. Kunz, C. Bruneau, D. Touchard, P.H. Dixneuf, Chem. Eur. J. 6 (2001) 1847-1857. 
[14] R. Castarlenas, M. Eckert, P.H. Dixneuf, Angew. Chem. Int. Ed. 44 (2005) 2576-2579.

[15] J.C. Conrad, H.H. Parnas, J.L. Snelgrove, D.E. Fogg, J. Am. Chem. Soc. 127 (2005) 11882-11883.

[16] A. Fürstner, O. Guth, A. Düffels, G. Seidel, M. Liebl, B. Gabor, R. Mynott, Chem. Eur. J. 7 (2001) 4811-4820.

[17] P.E. Romero, W.E. Piers, J. Am. Chem. Soc. 127 (2005) 50325033.

[18] M.S. Sanford, J.A. Love, R.H. Grubbs, J. Am. Chem. Soc. 123 (2001) 6543-6554.

[19] J.A. Love, M.S. Sanford, M.W. Day, R.H. Grubbs, J. Am. Chem. Soc. 125 (2003) 10103-10109.

[20] A. Fürstner, P.W. Davies, Chem. Commun. (2005) 2307-2320.

[21] U.H.F. Bunz, Acc. Chem. Res. 34 (2001) 998-1010.

[22] E.B. Bauer, J.A. Gladysz, R.H. Grubbs (Eds.), Handbook of Metathesis, vol. 2, Wiley-VCH, Weinheim, 2003, pp. 403-431.

[23] J.-P. Sauvage, C. Dietrich-Buchecker, Molecular Catenanes, Rotaxanes and Knots, Wiley-VCH, Weinheim, Germany, 1999.

[24] T.J. Hubin, D.H. Busch, Coord. Chem. Rev. 200-202 (2000) 5-52.

[25] S.J. Catrill, K.S. Chichak, A.J. Peters, J.F. Stoddart, Acc. Chem. Res. 38 (2005) 1-9.

[26] J.-P. Collin, C. Dietrich-Buchecker, P. Gaviña, M.C. Jimenez-Molero, J.-P. Sauvage, Acc. Chem. Res. 34 (2001) 477-487.

[27] B. Mohr, M. Weck, J.-P. Sauvage, R.H. Grubbs, Angew. Chem. Int. Ed. Engl. 36 (1997) 1308-1310.

[28] M. Weck, B. Mohr, J.-P. Sauvage, R.H. Grubbs, J. Org. Chem. 64 (1999) 994-1001.

[29] C. Dietrich-Buchecker, G. Rapenne, Chem. Commun. (1997) 2053-2054.

[30] T. Shima, E.B. Bauer, F. Hampel, J.A. Gladysz, Dalton Trans. (2004) 1012-1028.

[31] E.B. Bauer, F. Hampel, J.A. Gladysz, Organometallics 22 (2003) $5567-5580$.

[32] J. Ruwwe, J.M. Martín-Alvarez, C.R. Horn, E.B. Bauer, S. Szafert, T. Lis, F. Hampel, P.C. Cagle, J.A. Gladysz, Chem. Eur. J. 7 (2001) 3931-3950.

[33] E.B. Bauer, J. Ruwwe, J.M. Martín-Alvarez, T.B. Peters, J.C. Bohling, F. Hampel, S. Szafert, T. Lis, J.A. Gladysz, Chem. Commun. (2000) 2261-2262.

[34] C.R. Horn, J.M. Martín-Alvarez, J.A. Gladysz, Organometallics 21 (2002) 5386-5393.

[35] J.M. Martín-Alvarez, F. Hampel, A.M. Arif, J.A. Gladysz, Organometallics 18 (1999) 957-995.

[36] T. Shima, F. Hampel, J.A. Gladysz, Angew. Chem. Int. Ed. 43 (2004) 5537-5540.

[37] E.B. Bauer, F. Hampel, J.A. Gladysz, Adv. Synth. Catal. 346 (2004) $812-822$.

[38] E.B. Bauer, S. Szafert, F. Hampel, J.A. Gladysz, Organometallics 22 (2003) 2184-2186.

[39] A.-M.L. Fuller, D.A. Leigh, P.J. Lusby, A.M.Z. Slawin, D.B. Walker, J. Am. Chem. Soc. 127 (2005) 12612-12619.

[40] D.A. Leigh, P.J. Lusby, A.M.Z. Slawin, D.B. Walker, Angew. Chem. Int. Ed. 44 (2005) 4557-4564.

[41] A.-M.L. Fuller, D.A. Leigh, P.J. Lusby, I.D.H. Oswald, S. Parsons, D.B. Walker, Angew. Chem. Int. Ed. 43 (2004) 3914-3918.

[42] J.W.J. Knapen, A.W. van der Made, J.C. de Wilde, P.W.N.M. van Leeuwen, P. Wijkens, D.M. Grove, G. van Koten, Nature 372 (1994) 659-661.

[43] A.W. Kleij, R.A. Gossage, R.J.M. Klein Gebbink, N. Brinkmann, E.J. Reijerse, U. Kragl, M. Lutz, A.L. Spek, G. van Koten, J. Am. Chem. Soc. 122 (2000) 12112-12124.

[44] A.W. Kleij, R.A. Gossage, J.T.B.H. Jastrzebski, J. Boersma, G. van Koten, Angew. Chem. Int. Ed. 39 (2000) 176-178.

[45] P.A. Chase, R.J.M. Klein Gebbink, G. van Koten, J. Organomet. Chem. 689 (2004) 4016-4054.

[46] D. Astruc, F. Chardac, Chem. Rev. 101 (2001) 2991-3024.

[47] G.E. Oosterom, J.N.H. Reek, P.C.J. Kamer, P.W.N.M. van Leeuwen, Angew. Chem. Int. Ed. 40 (2001) 1828-1849.
[48] R. Kreiter, A.W. Kleij, R.J.M. Klein Gebbink, G. van Koten, Top. Curr. Chem. 217 (2001) 593.

[49] H.P. Dijkstra, G.P.M. van Klink, G. van Koten, Acc. Chem. Res. 35 (2002) 798-810.

[50] G.P.M. van Klink, H.P. Dijkstra, G. van Koten, Comp. Rendus Chim. 6 (2003) 1079-1085.

[51] M. Albrecht, G. van Koten, Angew. Chem. Int. Ed. 40 (2001) $3750-3781$

[52] M.E. van der Boom, D. Milstein, Chem. Rev. 103 (2003) 17591792.

[53] J.T. Singleton, Tetrahedron 59 (2003) 1837-1857.

[54] C.M. Jensen, Chem. Commun. (1999) 2443-2449.

[55] G. van Koten, Pure Appl. Chem. 61 (1989) 1681-1689.

[56] R.A. Gossage, L.A. van de Kuil, G. van Koten, Acc. Chem. Res. 31 (1998) 423-431.

[57] H.P. Dijkstra, P. Steenwinkel, D.M. Grove, M. Lutz, A.L. Spek, G. van Koten, Angew. Chem. Int. Ed. 38 (1999) 2186-2188.

[58] H.P. Dijkstra, C.A. Kruithof, N. Ronde, R. van de Coevering, D.J. Ramón, D. Vogt, G.P.M. van Klink, G. van Koten, J. Org. Chem. 68 (2003) 675-685.

[59] H.P. Dijkstra, M.D. Meijer, J. Patel, R. Kreiter, G.P.M. van Klink, M. Lutz, A.L. Spek, A.J. Canty, G. van Koten, Organometallics 20 (2001) 3159-3168.

[60] I.P. Beletskaya, A.V. Chuchuryukin, H.P. Dijkstra, G.P.M. van Klink, G. van Koten, Tetrahedron Lett. 41 (2000) 1081-1085.

[61] D.M. Grove, G. van Koten, J.N. Louwen, J.G. Noltes, A.L. Spek, H.J.C.J. Ubbels, J. Am. Chem. Soc. 104 (1982) 6609-6616.

[62] A.D. Dunn, S. Guillermic, Z. Chem. 28 (1998) 59-60.

[63] A.V. Chuchuryukin, P.A. Chase, H.P. Dijkstra, B.M.J.M. Suijkerbuijk, A.M. Mills, A.L. Spek, G.P.M. van Klink, G. van Koten, Adv. Synth. Catal. 347 (2005) 447-462.

[64] A.V. Chuchuryukin, H.P. Dijkstra, B.M.J.M. Suijkerbuijk, R.J.M. Klein Gebbink, G.P.M. van Klink, A.M. Mills, A.L. Spek, G. van Koten, Angew. Chem. Int. Ed. 42 (2003) 228-230.

[65] A.V. Chuchuryukin, H.P. Dijkstra, B.M.J.M. Suijkerbuijk, R.J.M. Klein Gebbink, G.P.M. van Klink, A.M. Mills, A.L. Spek, G. van Koten, Russ. J. Org. Chem. 39 (2003) 422-429.

[66] H.P. Dijkstra, A.V. Chuchuryukin, B.M.J.M. Suijkerbuijk, G.P.M. van Klink, A.M. Mills, A.L. Spek, G. van Koten, Adv. Synth. Catal. 344 (2002) 771-780.

[67] A.G. Osborne, G.T. Dimtrova, P. Galbaly, D.O. Hughes, C. Jones, A.L. Lipman, N. Wilstead, J. Chem. Res. S. (2002), pp. 4-4.

[68] P.T. Beurskens, G. Admiraal, G. Beurskens, W.P. Bosman, S. GarciaGranda, R.O. Gould, J.M.M. Smits, C. Smykalla, The DIRDIF99 program system, Technical Report of the Crystallography Laboratory, University of Nijmegen, The Netherlands, 1999.

[69] G.M. Sheldrick, SHELXL-97. Program for Crystal Structure Refinement, Universität Göttingen, Germany, 1997.

[70] H.D. Flack, Acta Cryst. A39 (1983) 876-881.

[71] A.L. Spek, J. Appl. Cryst. 36 (2003) 7-13.

[72] Y. Inoue, G.W. Gokel (Eds.), Cation Binding by Macrocycles, Marcel Dekker, New York, 1990.

[73] C.J. Pedersen, J. Am. Chem. Soc. 89 (1967) 7017-7036.

[74] E. Weber, F. Vögtle, Angew. Chem. Int. Ed. Engl. 19 (1980) $1030-1032$.

[75] G.R. Newkome, C.R. Marston, Tetrahedron 39 (1983) 20012008.

[76] S. Winstein, H.J. Lucas, J. Am. Chem. Soc. 60 (1938) 836-847.

[77] I. Krossing, A. Reisinger, Angew. Chem. Int. Ed. 42 (2003) 57255728.

[78] E. Keiken, O. Wiest, P. Helquist, M.E. Cucciolito, G. Flores, A. Vitagliano, P.-O. Norrby, Organometallics 24 (2005) 3737-3745.

[79] M.E. Cucciolito, G. Flores, A. Vitagliano, Organometallics 23 (2004) $15-17$.

[80] Q.-M. Wang, T.C.W. Mak, Chem. Eur. J. 9 (2003) 43-50.

[81] S. Inkuma, H. Ide, T. Yonekura, T. Funaki, S. Kondo, S. Shiobara, T. Yoshihara, S. Tobita, J. Nishimura, J. Org. Chem. 70 (2005) 1698-1703. 
[82] A.K. Chatterjee, T.-L. Choi, D.P. Sanders, R.H. Grubbs, J. Am. Chem. Soc. 125 (2003) 11360-11370.

[83] H.E. Blackwell, D.J. O'Leary, A.K. Chatterjee, R.A. Washenfelder, D.A. Bussmann, R.H. Grubbs, J. Am. Chem. Soc. 122 (2000) 58-71

[84] C. Pietraszuk, B. Marciniec, H. Fischer, Organometallics 19 (2000) 913-917.

[85] F. Diederich, P. Stang (Eds.), Templated Organic Synthesis, WileyVCH, New York, 2000.

[86] V.G. Albano, M. Di Serio, M. Monari, I. Orabona, A. Panunzi, F. Ruffo, Inorg. Chem. 41 (2002) 2672-2677.

[87] H. Jude, J.A. Krause Bauer, W.B. Connick, Inorg. Chem. 44 (2005) 1211-1220.

[88] H. Jude, J.A. Krause Bauer, W.B. Connick, Inorg. Chem. 43 (2004) 725-733.

[89] J. Huang, E.D. Stevens, S.P. Nolan, J.L. Peterson, J. Am. Chem. Soc. 121 (1999) 2674-2678.

[90] A. Fürstner, O.R. Thiel, L. Ackermann, H.-J. Schanz, S.P. Nolan, J. Org. Chem. 65 (2000) 2204-2207.

[91] S.S. Kinderman, J.H. van Maarseveen, H.E. Shoemaker, H. Hiemstra, F.P.J.T. Rutjes, Org. Lett. 3 (2001) 2045-2048.

[92] S.J. Miller, H.E. Blackwell, R.H. Grubbs, J. Am. Chem. Soc. 118 (1996) 9606-9614.

[93] T.R. Hoye, H. Zhao, Org. Lett. 1 (1999) 169-171.

[94] T.R. Hoye, H. Zhao, Org. Lett. 1 (1999) 1123-1125.
[95] V.I. Petkovska, T.E. Hopkins, D.H. Powel, K.B. Wagener, Macromolecules 38 (2005) 5878-5885.

[96] S.H. Hong, M.W. Day, R.H. Grubbs, J. Am. Chem. Soc. 126 (2004) 7414-7415.

[97] S.E. Lehman, J.E. Schwendeman, P.M. O’Donnell, K.B. Wagener, Inorg. Chem. Acta 345 (2002) 190-198.

[98] E. Thorn-Csányi, J. Dehmel, H.-D. Luginsland, J.U. Zilles, J. Mol. Catal. A 115 (1997) 29-35.

[99] D. Joe, L.E. Overman, Tetrahedron Lett. 38 (1997) 8635-8636.

[100] P.A. Chase, M. Gagliardo, G.P.M. van Klink, M. Lutz, A.L. Spek, G. van Koten, Organometallics 24 (2005) 2016-2019.

[101] R.G. Pearson, Hard and Soft Acids and Bases, in: Doweden, Hutchinson, Ross (Eds.), Strousbourg, PA, 1973.

[102] M.B. Smith, J. March, Advanced Organic Chemistry, fifth ed., John Wiley \& Sons, New York, 2001, pp. 770-773.

[103] C. Bergquist, B.M. Bridgewater, C.J. Harlan, J.R. Norton, R.A. Friesner, G. Parkin, J. Am. Chem. Soc. 122 (2000) 10581-10590.

[104] C.P. Radano, O.A. Scherman, N. Stingelin-Stutzmann, C. Müller, D.W. Breiby, P. Smith, R.A.J. Jannsen, E.W. Meijer, J. Am. Chem. Soc. 127 (2005) 12502-12503.

[105] B.M.J.M. Suijkerbuijk, M. Lutz, A.L. Spek, G. van Koten, R.J.M. Klein Gebbink, Org. Lett. 6 (2004) 3023-3026.

[106] P.A. Chase, B.M.J.M. Suijkerbuijk, G.P.M. van Klink, R.J.M. Klein Gebbink, G. van Koten, in preparation. 